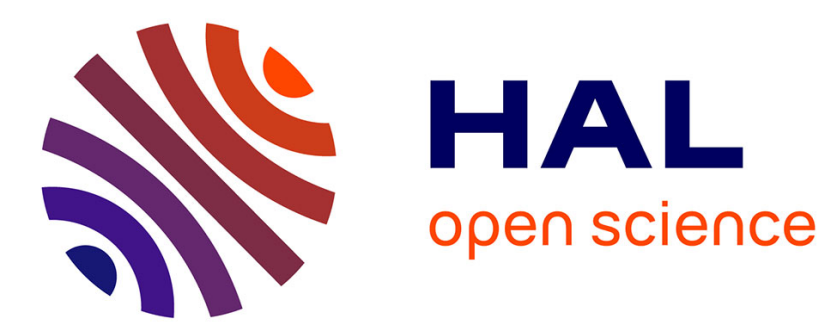

\title{
Theoretical Reassessment and Model Validation of Some Kinetic Parameters Relevant to $\mathrm{Si} / \mathrm{Cl} / \mathrm{H}$ Systems
}

\author{
Pascal Diévart, Laurent Catoire
}

\section{To cite this version:}

Pascal Diévart, Laurent Catoire. Theoretical Reassessment and Model Validation of Some Kinetic Parameters Relevant to Si/Cl/H Systems. Journal of Physical Chemistry A, 2021, 125 (12), pp.24462459. 10.1021/acs.jpca.0c11272 . hal-03201935

\section{HAL Id: hal-03201935 https://hal.science/hal-03201935}

Submitted on 19 Apr 2021

HAL is a multi-disciplinary open access archive for the deposit and dissemination of scientific research documents, whether they are published or not. The documents may come from teaching and research institutions in France or abroad, or from public or private research centers.
L'archive ouverte pluridisciplinaire HAL, est destinée au dépôt et à la diffusion de documents scientifiques de niveau recherche, publiés ou non, émanant des établissements d'enseignement et de recherche français ou étrangers, des laboratoires publics ou privés. 


\title{
A Theoretical Reassessment and Model Validation of some Kinetic Parameters relevant to $\mathrm{Si} / \mathrm{Cl} / \mathrm{H}$ systems
}

\section{Pascal Diévart* and Laurent Catoire}

\author{
Unité de Chimie et des Procédés (UCP), ENSTA Paris, Institut Polytechnique de Paris, 91120 \\ Palaiseau, France \\ E-mail : pascal.dievart@ensta-paris.fr \\ Tel : $+33(0) 181871991$
}

Corresponding author: Pascal DIÉVART (for complete contact information, see affiliation)

Subjects: silicon tetrachloride, theoretical calculations, kinetic modeling, shock tube, H-ARAS, combustion To cite: J. Phys. Chem. A 2021, 125, 12, 2446-2459 


\begin{abstract}
The increasing demand in silicon based materials requires the optimization of silicon deposit manufacturing processes and therefore a better understanding of the gas-phase reactivity of silicon precursors such as silicon tetrachloride $\left(\mathrm{SiCl}_{4}\right)$. In the present work, hydrogen atoms resonance absorption spectroscopy (H-ARAS) have been used to investigate the high temperature reactivity of $\mathrm{SiCl}_{4}$ behind reflected shock waves at $\sim 1.5 \mathrm{~atm}$ in the presence of either ethyl iodide or molecular hydrogen, used as $\mathrm{H}$ atoms precursors. Several key reactions of $\mathrm{SiCl}_{4}$ and its main gas-phase decomposition products $\left(\mathrm{SiCl}_{3}, \mathrm{Cl}, \mathrm{SiHCl}_{3}, \mathrm{SiHCl}_{2}\right)$ have been determined theoretically. The structures and vibrational frequencies of reactants, products, and tight transition states were determined at the B2PLYP-D3/aug-cc-pVTZ level, and final single point energies refined from extrapolated $\operatorname{RCCSD}(\mathrm{T}) / \mathrm{aug}-\mathrm{cc}-\mathrm{pVnZ}(\mathrm{n}=\mathrm{D}, \mathrm{T}$, and Q) calculations. The minimum-energy paths of barrierless reactions were calculated at the NEVPT2 level. Final rate constants were then derived from Transition State Theory (TST) and Variational TST/Master Equation analysis within the rigid rotor harmonic oscillations framework. A kinetic mechanism was assembled, based on the present ab initio calculations, to successfully model and interpret the experimental absorption profiles. Sensitivity analysis unambiguously highlighted the need to account for the pressure dependence in the $\mathrm{SiCl}_{4}$ decomposition $\left(\mathrm{SiCl}_{4} \rightleftarrows \mathrm{SiCl}_{3}+\mathrm{Cl}\right.$ ), while discarding previous theoretical and experimental determinations of this rate constant.
\end{abstract}




\section{Introduction}

Silicon is nowadays regarded as an important material. Indeed, it is a component of several technologies such as solar panels, semi-conductors, computers, engines, household appliances, etc. Silicon tetrachloride $\left(\mathrm{SiCl}_{4}\right)$ is used or may be used as a silicon precursor in several manufacturing processes, such as the production of $\mathrm{Si}_{3} \mathrm{~N}_{4}$ by ammonolysis, the growth of silicon films or thin silicon nanowires by hydrogen reduction, thermal decomposition or chemical vapor deposition (CVD), production of $\mathrm{Si}$ nanoparticles by plasma assisted hydrogenation, and fused silica glass synthesis by oxidation of $\mathrm{SiCl}_{4} / \mathrm{H}_{2}$ mixtures. It is therefore crucial to study $\mathrm{SiCl}_{4}$ chemistry and its kinetics to provide the community and the industry with detailed chemical models to be implemented in numerical codes designed for the optimization of the aforementioned applications.

Ammonia $\mathrm{NH}_{3}$ and hydrogen $\mathrm{H}_{2}$ are the main co-reactants employed in $\mathrm{SiCl}_{4}$ based applications, and as such the chemistry of $\mathrm{SiCl}_{4} / \mathrm{H}$ and $\mathrm{SiCl}_{4} / \mathrm{H}_{2}$ mixtures is of outmost importance and is the focus of the present study.

In spite of its importance for the reactivity of the $\mathrm{SiCl}_{4} / \mathrm{H}_{2}$ mixtures, the direct reaction of $\mathrm{H}$ atoms with $\mathrm{SiCl}_{4}$ has been the aim of only one experimental study ${ }^{1}$ limited to the $1530-1730 \mathrm{~K}$ temperature range.

$$
\mathrm{R}_{1} \quad \mathrm{SiCl}_{4}+\mathrm{H} \rightleftarrows \mathrm{SiCl}_{3}+\mathrm{HCl}
$$

Rate constants were obtained by monitoring the $\mathrm{H}$ atom ARAS profile decay and assuming a pseudo first-order kinetics, without any contributions from secondary chemistry. However, since this pioneering work, two theoretical studies by Ge et al. ${ }^{2}$ and Zhang et al. ${ }^{3}$ have been released. The calculations of Ge et al. supported the experimental determinations whereas the results of Zhang et al. suggested that the experimental values overestimate the real rate constant. Moreover, later experimental studies on $\mathrm{SiCl}_{4}$ thermal decomposition ${ }^{4}$ suggested that the first-order assumption did not hold and thus that secondary chemistry initiated by $\mathrm{SiCl}_{4}$ decomposition may account for a large extent to the $\mathrm{H}$ atom consumption observed experimentally $\left(\mathrm{SiCl}_{3}+\mathrm{H}\right.$ for example) as indicated by a rate of consumption analysis. Indeed, using the experimental rate constant of Kunz and Roth for $\mathrm{k}_{2}$ and the value of Catoire et al. for $\mathrm{k}_{1}$ reveals that $\mathrm{SiCl}_{4}$ is consumed for one third by thermal decomposition at $1530 \mathrm{~K}$ and that the abstraction reaction $R_{1}$ is totally overwhelmed by the reaction $R_{2}$ at higher temperatures $(1725 \mathrm{~K})$.

$$
\mathrm{R}_{2} \quad \mathrm{SiCl}_{4}(+\mathrm{M}) \rightleftarrows \mathrm{SiCl}_{3}+\mathrm{Cl}(+\mathrm{M})
$$

As a consequence, the rate constant of reaction $R_{1}$ must be reassessed in order to settle the discrepancy between the experimental data and some of the theoretical works. While doing so, $\mathrm{R}_{2}$ must also be reexamined, along with reactions of $\mathrm{SiCl}_{\mathrm{x}}$ species with $\mathrm{H}$-atoms, such as $\mathrm{SiCl}_{3} / \mathrm{SiCl}_{2}+\mathrm{H}$, reactions that have never been specifically investigated neither experimentally nor theoretically.

The combination of a theoretical approach and the development of detailed kinetic models has been applied recently to trichlorosilane gas phase reactivity by Ge et al. ${ }^{2}$ and Ravasio et al. ${ }^{5}$, but none of these 
two groups have confronted their models against experimental data. Therefore this paper is devoted to the comparison of previously published or unpublished experimental data with the predictions of a model in order to emphasize some interesting features of silicon species reactions, including those for which the kinetics is believed to be known.

\section{Experimental and Theory}

\subsection{Experiments}

Experiments were performed by investigating the reactivity of $\mathrm{SiCl}_{4} / \mathrm{C}_{2} \mathrm{H}_{5} \mathrm{I}^{1}$ and $\mathrm{SiCl}_{4} / \mathrm{H}_{2}$ mixtures behind reflected shock waves, providing an instantaneous heating of the system. The shock tube (internal diameter $79 \mathrm{~mm}$ ) consists of a $3.5 \mathrm{~m}$ long driver section and a $5.7 \mathrm{~m}$ long driven section separated by a thin aluminum diaphragm, and has been described in further details in previous studies ${ }^{6,7}$. A schematic of the system is available in the Supplementary Information (Figure S1). High purity gases (Ar >99.9999 mol\%, $\left.\mathrm{H}_{2}>99.9999 \mathrm{~mol} \%\right)$ and liquids $\left(\mathrm{SiCl}_{4}>99.999 \%, \mathrm{C}_{2} \mathrm{H}_{5} \mathrm{I}>99 \%\right)$ were used for the reacting mixtures. These mixtures were manometrically prepared in a separate stainless steel vessel prior injection in the shock tube.

For temperatures between 1500 and $1750 \mathrm{~K}$ and pressures around $1.5 \mathrm{bar}$, the $\mathrm{H}$-atom time profiles were monitored by atomic resonance absorption spectroscopy (ARAS) at the $\mathrm{L}_{\alpha}$ line $(121.6 \mathrm{~nm})$. The ARAS technique is based on the strong absorption of atoms for the resonance wavelengths of their respective absorption/emission spectra. The ARAS diagnostic system (see Figure S1) consists of a microwave excited discharge lamp (6 mbar, $50 \mathrm{~W}$ ) fed with a flowing gas mixture of $1 \% \mathrm{H}_{2}$ in helium, an optical absorption path in the shock tube, a $1 \mathrm{~m}$ vacuum U.V. monochromator, and a solar blind photomultiplier. The high sensitivity of the ARAS absorption enables working with highly diluted mixtures (a few ppm of reactants in argon), therefore ensuring isothermal and isobaric conditions.

$\mathrm{SiCl}_{4} / \mathrm{H}_{2}$ experiments were devised to be mostly sensitive to $\mathrm{R}_{2}$ and to a lesser extent to $\mathrm{R}_{1}$. At high temperature, $\mathrm{SiCl}_{4}$ is expected to first release chlorine atoms that will react with $\mathrm{H}_{2}$ to form hydrogen chloride $\mathrm{HCl}$ and an $\mathrm{H}$-atom, which, providing that some $\mathrm{SiCl}_{4}$ is still present in the reacting mixture, further reacts with $\mathrm{SiCl}_{4}$ (and also secondary products). Three different compositions were considered

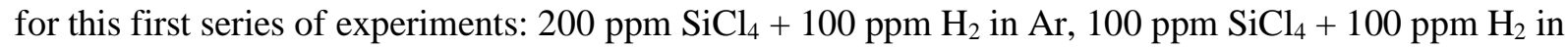
$\mathrm{Ar}$, and $50 \mathrm{ppm} \mathrm{SiCl}_{4}+100 \mathrm{ppm} \mathrm{H}_{2}$ in $\mathrm{Ar}$.

$$
\begin{array}{ll}
\mathrm{R}_{2} & \mathrm{SiCl}_{4}(+\mathrm{M}) \rightleftarrows \mathrm{SiCl}_{3}+\mathrm{Cl}(+\mathrm{M}) \\
\mathrm{R}_{14} & \mathrm{H}_{2}+\mathrm{Cl} \rightleftarrows \mathrm{HCl}+\mathrm{Cl} \\
\mathrm{R}_{1} & \mathrm{SiCl}_{4}+\mathrm{H} \rightleftarrows \mathrm{SiCl}_{3}+\mathrm{HCl}
\end{array}
$$

On the other hand, $\mathrm{SiCl}_{4} / \mathrm{C}_{2} \mathrm{H}_{5} \mathrm{I}$ experiments were initially designed to infer the rate constant of $\mathrm{R}_{1}$. Indeed, ethyl iodide was used as an $\mathrm{H}$-atom precursor, since, at temperatures above $1500 \mathrm{~K}$, it quickly decomposes into an ethyl radical, which then gives an ethylene molecule and an $\mathrm{H}$-atom. Like the first 
series of measurements, three compositions were considered: $101 \mathrm{ppm} \mathrm{SiCl}_{4}+3 \mathrm{ppm}_{2} \mathrm{H}_{5} \mathrm{I}$ in $\mathrm{Ar}$, $50 \mathrm{ppm} \mathrm{SiCl} l_{4}+5.6 \mathrm{ppm} \mathrm{C}_{2} \mathrm{H}_{5} \mathrm{I}$ in $\mathrm{Ar}$, and $60.7 \mathrm{ppm} \mathrm{SiCl}_{4}+6 \mathrm{ppm} \mathrm{C}_{2} \mathrm{H}_{5} \mathrm{I}$ in Ar.

$$
\begin{aligned}
& \mathrm{C}_{2} \mathrm{H}_{5} \mathrm{I}(+\mathrm{M}) \rightleftarrows \mathrm{C}_{2} \mathrm{H}_{5}+\mathrm{I}(+\mathrm{M}) \\
& \mathrm{C}_{2} \mathrm{H}_{5}(+\mathrm{M}) \rightleftarrows \mathrm{C}_{2} \mathrm{H}_{4}+\mathrm{H}(+\mathrm{M})
\end{aligned}
$$

This second series of experiments has been employed, as mentioned in the introduction, to access $\mathrm{k}_{1}$ values, in the assumption that (i) secondary chemistry is negligible, based on the large excess of $\mathrm{SiCl}_{4}$ in comparison to $\mathrm{C}_{2} \mathrm{H}_{5} \mathrm{I}$, (ii) thermal decomposition of $\mathrm{SiCl}_{4}$ is unimportant, and (iii) absorption by secondary products at the $\mathrm{L}_{\alpha}$ line was extremely weak. The second assumption was rationalized by an apparent stable absorption profile of $\mathrm{SiCl}_{4} / \mathrm{Ar}$ mixtures for a $1 \mathrm{~ms}$ time window after the reflected shock wave.

Nevertheless, rather than using experimental profiles to determine individual rate constants as in the original articles, the strategy adopted herein is to use the experimental profile to test and validate a kinetic model in which key rate constants will be determined a priori from theoretical calculations. However, in order to compare model predictions to the experimental profiles, it is mandatory to relate the absorption profiles to $\mathrm{H}$-atom and $\mathrm{SiCl}_{4}$ concentration.

\subsection{Modeling and absorption-concentration relationship}

Through the Beer-Lambert law, absorption and concentration are related according to

$$
A(t)=1-\exp \left(-l \sum_{i} \sigma_{i}[i(t)]^{n_{i}}\right)
$$

(Equation 1)

Where 1 is the absorption path length $(\mathrm{cm}), \sigma_{i}$ the absorption coefficient of the species $\mathrm{i}\left(\mathrm{cm}^{2}\right),[\mathrm{i}(\mathrm{t})]$ the concentration of the species $\mathrm{i}\left(\mathrm{cm}^{-3}\right)$ at instant $\mathrm{t}$, and $\mathrm{n}_{\mathrm{i}}$ the concentration exponent (usually equal to unity). In this relation, absorption coefficients and concentration exponent must be determined to compare simulated species profiles and absorption profile.

For the hydrogen atom, the ARAS calibration curve is generally obtained using the well-known thermal decomposition of $\mathrm{H}_{2}$ at high temperatures (> $2500 \mathrm{~K}$ ), whereas $\mathrm{H}_{2} / \mathrm{N}_{2} \mathrm{O}$ mixtures are employed at lower temperatures $(1000-2000 \mathrm{~K})$. In the original study, Catoire et al. ${ }^{1}$ have determined $\sigma_{\mathrm{H}}=1.110^{-11} \mathrm{~cm}^{2}$ and $\mathrm{n}_{\mathrm{H}}=0.80$ for high temperatures $(>2000 \mathrm{~K})$ and Kunz and Roth ${ }^{4}$ have later determined $\sigma_{\mathrm{H}}=1.310^{-}$ ${ }^{8} \mathrm{~cm}^{2}$ and $\mathrm{n}_{\mathrm{H}}=0.56$ between 1300 and $1900 \mathrm{~K}$.

Although most of the ARAS signal may be attributed to H-atom absorption, contribution of silicon and chlorine species cannot be overlooked. Mével and co-workers ${ }^{8}$ have determined the temperature dependence of the absorption coefficient of $\mathrm{SiCl}_{4}\left(\sigma_{\mathrm{SiCl} 1}\right), \mathrm{SiCl}_{3}\left(\sigma_{\mathrm{SiC} 13}\right), \mathrm{SiCl}_{2}\left(\sigma_{\mathrm{SiCl} 2}\right)$ and $\mathrm{Cl}\left(\sigma_{\mathrm{Cl}}\right)$ 
(assuming a unit concentration exponent) at the $\mathrm{L}_{\alpha}$ line from $\mathrm{SiCl}_{4}$ decomposition experiments, which will thereafter be used to account for these species in the reacting mixture absorption.

$$
A(t)=1-\exp \left[-\mathrm{l}\left(\sigma_{H}[H(t)]^{0.56}+\sigma_{\text {SiCl }_{4}}\left[\operatorname{SiCl}_{4}(t)\right]+\sigma_{\text {SiCl }_{3}}\left[\operatorname{SiCl}_{3}(t)\right]+\sigma_{\text {SiCl }_{2}}\left[\operatorname{SiCl}_{2}(t)\right]+\sigma_{C l}[\mathrm{Cl}(t)]\right)\right]
$$

(Equation 2)

The detailed kinetic model proposed to interpret the experimental absorption profiles is discussed in section 3.2.1. Kinetic simulations were performed with the closed homogeneous batch reactor under the assumption of constant temperature and constant pressure as implemented in Chemkin Pro9.

\subsection{Computational details}

Theoretical calculations presented in this study were performed with Gaussian 09 Revision $\mathrm{D}^{10}$ for geometry optimizations and frequency calculations employing M06-2x and second-order perturbative single reference B2PLYP methods, inclusive Grimme's dispersion correction terms in both cases. Harmonic frequencies and zero-point vibrational energies were scaled according to the factors $\left(\lambda_{\mathrm{Har}} / \lambda_{\mathrm{ZPVE}}\right)$ published by Kesharwani et al. ${ }^{11}$ for B2PLYP optimized structures $\left(\lambda_{\mathrm{Har}}=1.0029\right.$ and 0.9999 and $\lambda_{\mathrm{ZPVE}}=0.9866$ and 0.9837 with aug-cc-pVDZ and aug-cc-pVTZ basis sets, respectively) and Truhlar et al. ${ }^{12}$ for M06-2x geometries $\left(\lambda_{\text {Har }}=0.993\right.$ and $\lambda_{\text {Har }}=0.979$ with aug-cc-pVDZ basis set).

Refined spin-restricted coupled cluster single-double with triple perturbative energies were computed with the Orca software (revision 4.2.1) ${ }^{13,14}$. For reactions requiring multi-reference N-Electron Valence State Perturbation Theory (NEVPT2), the energy calculations were also performed with Orca. All these calculations did employ double, triple, and quadruple- $\zeta$ Dunning's basis sets ${ }^{15}$, either augmented or not with diffuse functions. Extrapolation of the HF, $\operatorname{CCSD}(\mathrm{T})$ correlation and NEVPT2 energies to the infinite limit was achieved through a mixed Gaussian/exponential model:

$$
E_{v \infty Z}=\frac{\left(1+e^{2}\right) E_{v D Z}-\left(e+e^{3}+e^{5}\right) E_{v T Z}+e^{6} E_{v Q Z}}{(e-1)\left(e^{5}-e^{2}-1\right)}
$$

Details on the calculations are provided along with the discussion of the rate constants herein reinvestigated.

The Multiwell package ${ }^{16}$ was used to derive the pressure independent rate constants, within the framework of the Rigid Rotor Harmonic Oscillator, regardless of whether they exhibit a well-defined saddle point (Thermo module) or proceed barrierless towards the products (Variational TST, ktools module).

The temperature and pressure dependent rate constants of decomposition or chemically activated reactions were computed with $\mathrm{Mesmer}^{17}$ by solving an E-resolved master equation. A single exponential down model was considered for the deactivation collisions, and the model parameters for $\mathrm{Ar}, \mathrm{N}_{2}$, and $\mathrm{He}$ as bath gases were adopted from the work of Jasper and Miller ${ }^{18}$ on methane decomposition, whereas 
the parameters proposed for methane were adopted for $\mathrm{SiCl}_{4}$ as the bath gas. The Lennard-Jones parameters requested to run the ME calculations were obtained by fitting an exp/6 intermolecular potential model on MP2/aug-cc-pVTZ spherically-averaged interaction potentials between helium and the relevant $\mathrm{SiH}_{\mathrm{x}} \mathrm{Cl}_{\mathrm{y}}$ species (see Supplementary Materials). The Lennard-Jones parameters ( $\sigma$ and $\epsilon$ ) obtained in this study are 6.90, 6.63, and $6.31 \AA$ and 156, 118, and $95 \mathrm{~K}$ for $\mathrm{SiCl}_{4}, \mathrm{SiHCl}_{3}$, and $\mathrm{SiHCl}_{2}$, respectively. They differ significantly from the estimated parameters proposed by Moore et al. ${ }^{19}(5.64 \AA$ and $390 \mathrm{~K}$ for $\left.\mathrm{SiCl}_{4}\right)$.

\section{Results and Discussion}

\subsection{Theoretical calculations}

\subsubsection{Reaction $\mathrm{SiCl}_{4}+\mathrm{H}\left(\mathrm{R}_{1}\right.$ and $\left.\mathrm{R}_{5}\right)$}

After the publication of the first (and last) kinetic experimental work, the features of reaction $\mathrm{R}_{1}$ have been investigated theoretically, spanning a large set of theoretical methods. Zhang et al. ${ }^{3}$ were the first to report a predicted rate constant, however limited to the same temperature range as the experimental data of Catoire et al $^{1}$. The potential energy surface of the reaction was investigated based on MP2/6$311 \mathrm{G}(\mathrm{d}, \mathrm{p})$ optimized structures and final single point energies evaluated at the UMP4(SDTQ) and UQCISD(T) level of theory with the same basis set. The direct chlorine abstraction was found to occur via a $C_{3 \mathrm{v}}$ symmetry transition state with a ZPVE corrected barrier of 24.34 and $22.62 \mathrm{kcal} \mathrm{mol}^{-1}$ (with respect to the reactants) according to UMP4(STDQ) and QCISD(T) calculations, respectively. They then derived a rate constant applying canonical variational transition state theory inclusive smallcurvature tunneling (CVT/SCT). Although the predicted rate constants are consistent with the lower limit uncertainty of the experimental ones (see Figure 1), the computed apparent activation energy in the temperature range considered, $27.07 \mathrm{kcal} \mathrm{mol}^{-1}$, is much higher than the experimental energy barrier, $9.54 \pm 5.17 \mathrm{kcal} \mathrm{mol}^{-1}$.

Later, Ge et al. ${ }^{2}$ assembled a methyltrichlorisilane pyrolysis detailed kinetic model in which a large set of rate constants, amid which $\mathrm{R}_{1}$, were obtained from ab initio calculations. Energetics were obtained from CCL/cc-pVTZ//MP2/cc-pVDZ method, and rate constants derived from classical transition state theory without tunneling corrections. Their predicted rate constant revealed to be in excellent agreement with the experimental values of Catoire et al., as it can be seen in Figure 1.

Besides these two studies, other groups investigated the energetics of the reaction using either various DFT methods or molecular dynamic simulations. The main outcome of those works was the reaction energy barrier, which are listed in Table 1. It can be observed that the results span a large range of energy, from 9.7 to $24.3 \mathrm{kcal} \mathrm{mol}^{-1}$. The lowest barrier is obtained from MD simulations whereas $a b$ 
initio methods (MP4, QCISD, CCSD) computes the largest, and DFT methods display intermediate values ranging from 11 to $18 \mathrm{kcal} \mathrm{mol}^{-1}$, the popular B3LYP functional being on the lower end.

The large variability in the computed energy barriers motivated the reinvestigation of the potential energy surface of reaction $R_{1}$. In addition to the abstraction channel, the substitution path $R_{5}$ was also considered

$$
\mathrm{R}_{5} \quad \mathrm{SiCl}_{4}+\mathrm{H} \rightleftarrows \mathrm{SiHCl}_{3}+\mathrm{Cl}
$$

Reactants, products and transition states geometries for the two reaction paths were first optimized with the global-hybrid meta-GGA M06-2x inclusive Grimme's dispersion correction coupled to the augmented double-zeta basis set (M06-2x-D3/aug-cc-pVDZ). Final spin-restricted CCSD(T) energies were then obtained from successive calculations with double, triple, and quadruple- $\zeta$ basis sets extrapolated to the infinite limit.

The abstraction reaction proceeds through a $\mathrm{C}_{3 \mathrm{v}}$ symmetry transition state, consistent with the findings of Zhang et al. ${ }^{3}$ However, the Si-Cl breaking bond and the $\mathrm{H}-\mathrm{Cl}$ forming bond herein calculated are shorter and longer, respectively, than those reported by Zhang et al. (2.27 $\AA$ vs. $2.29 \AA$ and $1.58 \AA$ vs. $1.50 \AA$, respectively). The calculated $\mathrm{Si}-\mathrm{Cl}$ bond lengths in the reactant and the TS are almost identical (2.05 and $2.06 \AA$ ) but longer by the $0.03 \AA$ than those reported by Zhang et al. ${ }^{3}$

The $T_{1}$ diagnostic values are rather modest, ranging from 0.006 to 0.021 , for the abstraction path $R_{1}$ highlighting the weak multi-reference character of $\mathrm{TS}_{1}$. The forward energy barrier is computed at $20.8 \mathrm{kcal} \mathrm{mol}^{-1}$, which is on the upper range of the previously published energy barriers. This energy is nevertheless $1.8 \mathrm{kcal} \mathrm{mol}^{-1}$ lower than the reported QCISD(T) barrier of Zhang et al. ${ }^{3}$ but higher than the $\operatorname{CCSD}(\mathrm{T})$ barrier of Ge et al. ${ }^{20}$ by the same extent. The discrepancy with the values of Zhang et al. is even larger for the reverse energy barrier, which is to be related with the exceptionally low heat of reaction calculated. Indeed, the QCISD(T)/6-311G(d,p)//UMP2/6-311G(d,p) calculations return a $\Delta \mathrm{H}_{\mathrm{f}, 0 \mathrm{~K}}$ of $0.7 \mathrm{kcal} \mathrm{mol}^{-1}$ whereas the present study predicts a value of $7.7 \mathrm{kcal} \mathrm{mol}^{-1}$. Su and Schlegel ${ }^{21}$ and Bauschlicher and Partridge ${ }^{22}$ have determined the heat of formation for $\mathrm{SiCl}_{3}$, which, combined with the NIST values for $\mathrm{SiCl}_{4}, \mathrm{H}$, and $\mathrm{HCl}$ lead to a reaction enthalpy of $\sim 9 \mathrm{kcal} \mathrm{mol}^{-1}$, in line with the present predictions.

The energy barrier for the substitution channel $\left(56.7 \mathrm{kcal} \mathrm{mol}^{-1}\right)$ is calculated to be significantly larger than the one for the abstraction path. However, the saddle point exhibits a large $\mathrm{T}_{1}$ diagnostic $(0.040)$, questioning the accuracy of single-reference energies. NEVPT2 $(3,3) / \mathrm{cc}-\mathrm{pV} \infty \mathrm{Z}$ single points energy calculations have been carried out with the M06-2x-D3/aug-cc-pVDZ optimized structures. These multi-reference calculations provide a forward energy barrier of $53.3 \mathrm{kcal} \mathrm{mol}^{-1}$, slightly lower by $3.5 \mathrm{kcal} \mathrm{mol}^{-1}$ than the $\mathrm{RCCSD}(\mathrm{T})$ values but nonetheless confirming that this channel $\left(\mathrm{R}_{5}\right)$ is unlikely to compete with the abstraction reaction $\mathrm{R}_{1}$. 
Table 1: Summary of energy barrier and heat of reaction $\left(\mathrm{kcal} \mathrm{mol}^{-1}\right)$ reported in the literature and calculated in the present study for the reaction $\mathrm{SiCl}_{4}+\mathrm{H} \rightleftarrows \mathrm{SiCl}_{3}+\mathrm{HCl}\left(\mathrm{R}_{1}\right)$

\begin{tabular}{|c|c|c|c|c|}
\hline method & type & barrier & $\Delta \mathbf{H}_{298 K}$ & reference \\
\hline MPW1K/6-31+G(d,p) & DFT & $18.4^{\mathrm{a}}$ & 2.8 & 23 \\
\hline BH\&HLYP/6-31+G(d,p) & DFT & $18.3^{\mathrm{a}}$ & -0.8 & 23 \\
\hline B3LYP/6-31+G(d,p) & DFT & $11.6^{\mathrm{a}}$ & -4.4 & 23 \\
\hline B3LYP/6-311++G(3df,2p) & DFT & 12.9 & $-1.2^{\mathrm{b}}$ & 24 \\
\hline PW91 & MD & 9.7 & - & 24 \\
\hline UMP4(SDTQ)/6-311G(d,p)//MP2/6-311G(d,p) & $a b$ initio & 24.3 & 1.9 & 3 \\
\hline UQCISD(T)/6-311G(d,p)//MP2/6-311G(d,p) & $a b$ initio & 22.6 & 0.7 & 3 \\
\hline CCSD(T)/aug-cc-pVTZ//MP2/aug-cc-pVDZ & $a b$ initio & 19.2 & 4.0 & 20 \\
\hline CCCL/cc-pVTZ//MP2/cc-pVDZ & $a b$ initio & 20.9 & 4.5 & 2 \\
\hline $\mathrm{CCSD}(\mathrm{T}) / \mathrm{cc}-\mathrm{pV} \infty \mathrm{Z} / / \mathrm{M} 06-2 \mathrm{x}-\mathrm{D} 3 /$ aug-cc-pVDZ & $a b$ initio & 20.8 & 7.7 & present work \\
\hline CCSD(T)/cc-p $\infty V Z / / B 2 P L Y P-D 3 / a u g-c c-p V D Z$ & $a b$ initio & 20.3 & 7.3 & present work \\
\hline CCSD(T)/cc-p $\infty$ VZ//B2PLYP-D3/aug-cc-pVTZ & $a b$ initio & 20.7 & 7.4 & present work \\
\hline CCSD(T)/aug-cc-p $\infty V Z / / B 2 P L Y P-D 3 / a u g-c c-p V T Z$ & $a b$ initio & 20.5 & 7.7 & present work \\
\hline
\end{tabular}

Sensitivity of the energy barriers on the method and basis sets employed for the structure optimization has been tested. M06-2x/aug-cc-pVDZ structures were further optimized with the double hybrid B2PLYP-D3 method associated with either an augmented double- or triple- $\zeta$ basis set, and RCCSD(T) extrapolated energies computed with the new structures. These energies are displayed in Table 1. The change of the level of theory for the geometry optimization results in a small elongation of all the bond lengths by $0.01 \AA$ and in a small decrease of the forward energy barrier $\left(-0.5 \mathrm{kcal} \mathrm{mol}^{-1}\right)$ and the heat of reaction for $\mathrm{R}_{1}$. Adopting a triple- $\zeta$ basis set rather than a double one shortens the $\mathrm{Si}-\mathrm{Cl}(2.04 \AA)$ and the forming $\mathrm{H}-\mathrm{Cl}$ bonds $\left(1.54 \AA\right.$ ), increases slightly the energy barrier $\left(+0.4 \mathrm{kcal} \mathrm{mol}^{-1}\right)$ but does not affect the enthalpy of the reaction. Based on B2PLYP-D3/aug-cc-pVTZ optimized geometries, the influence of adding diffuse functions to the basis sets employed in the energy calculations has been considered and is found limited. 


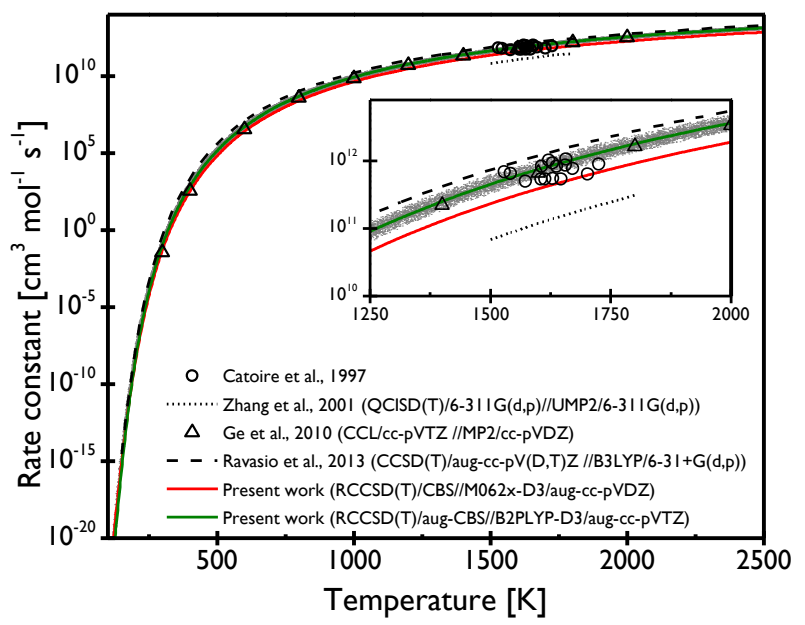

Figure 1: Rate constants for the reaction $\mathrm{R}_{1} \mathrm{SiCl}_{4}+\mathrm{H} \rightleftarrows \mathrm{SiCl}_{3}+\mathrm{HCl}$.

In spite of our efforts, no optimized structures for TS1b could be identified when using the double hybrid methods. Therefore, the final rate constants adopted in this study and reported in Table 3 is the one calculated from M06-2x-D3 structures with the confidence that this reaction will take no part in $\mathrm{SiCl}_{4}$ overall chemistry.

Predicted rate constants for reaction $\mathrm{R}_{1}$ calculated with the M06-2x-D3/aug-cc-pVDZ and B2PLYPD3/aug-cc-pVTZ rovibrational properties combined with RCCSD(T)/cc-pV $\infty Z$ and RCCSD(T)/aug-cc$\mathrm{pV} \infty \mathrm{Z}$ energetics, respectively, are displayed in Figure 1. The M06-2x-D3 predicted rate constants are about two times lower than the B2PLYP-D3 rate constants, regardless of the difference in the energy barriers. The present calculations are in close agreement with the experimental data of Catoire et al. and the theoretical values of Ge et al. and Ravasio et al. Therefore, the theoretical data of Zhang et al. are further confirmed to be far off and should be definitively discarded from kinetics database. In order to estimate the sensitivity of the predicted rate constants to the calculated quantum parameters, upper/lower bounds of $\pm 10 \%$ on the vibrational frequencies $v, \pm 5 \%$ on the external moment of inertia $\mathrm{I}$, and $\pm 0.5 \mathrm{kcal} \mathrm{mol}^{-1}$ on the forward and reverse energy barriers $\mathrm{E}$ were assigned. Choosing randomly different values for $\mathrm{x}, \mathrm{y}$, and $\mathrm{z}(-1<\mathrm{x}, \mathrm{y}, \mathrm{z}<1)$, modified input parameters could be evaluated as

$$
\begin{aligned}
v_{i} & =(0.9+0.2 x) v_{i, 0} \\
I_{i} & =(0.95+0.1 y) I_{i, 0} \\
E_{i} & =(-0.5+z)+E_{i, 0}
\end{aligned}
$$

and used to run a TST analysis for ten temperatures also chosen randomly. Repeating this procedure a few thousand times resulted in the dot cloud shown in Figure 1, which provides upper and lower uncertainties on the predicted rate constant. The relative uncertainty on the rate constant is found to be nearly temperature independent, with a lower bound of $-30 \%$ and an upper bound of $40 \%$. The final 
recommended rate constant to be implemented in kinetic models is well fitted by the modified Arrhenius expression

$$
k\left[\mathrm{~cm}^{3} \mathrm{~mol}^{-1} \mathrm{~S}^{-1}\right]=(1.07 \pm 0.18) \cdot 10^{9} \cdot T^{1.70 \pm 0.02} \cdot e^{-\frac{9657 \pm 24}{T}}
$$

3.1.2. Reactions on the $\mathrm{SiCl}_{3}+\mathrm{H}$ potential energy surface $\left(\mathrm{R}_{6}-\mathrm{R}_{8}\right)$

The trichlorosilyl radical, instead of decomposing into dichlorosilylene $\mathrm{SiCl}_{2}$ and a chlorine atom $\left(\mathrm{R}_{3}\right)$, can also react with chain carriers such as $\mathrm{H}$ atom. The reaction between $\mathrm{SiCl}_{3}$ and $\mathrm{H}$-atoms can either occur on a triplet potential energy surface $\left(R_{6 b}\right)$ or a singlet surface $\left(R_{6 a}, R_{7}\right.$, and $\left.R_{8}\right)$. Both potential surfaces are displayed in Figure 2 along with the energies calculated at the RCCSD(T)/aug-ccpVœZ//B2PLYP-D3/aug-cc-pVTZ for the different stationary and saddle points.

On the triplet surface, the reaction proceeds via a direct Cl-abstraction reaction $\left(\mathrm{R}_{6 \mathrm{~b}}\right)$ yielding hydrogen chloride and triplet ${ }^{3} \mathrm{SiCl}_{2}$. The energy barrier associated to this bimolecular reaction is $25.4 \mathrm{kcal} \mathrm{mol}^{-1}$ and the energy products lies $17.55 \mathrm{kcal} \mathrm{mol}^{-1}$ above the reactants, resulting in an unlikely reaction. Combined with the present energetics and rovibrational properties, a RRHO-TST analysis with an Eckart tunneling correction yields a rate constant of $\mathrm{k}_{6 \mathrm{~b}}=1.0010^{10} \mathrm{~T}^{1.345} \mathrm{e}^{-12596 / \mathrm{T}}$ (in $\mathrm{cm}^{3} \mathrm{~mol}^{-1} \mathrm{~s}^{-1}$ between 200 and $3000 \mathrm{~K})$.

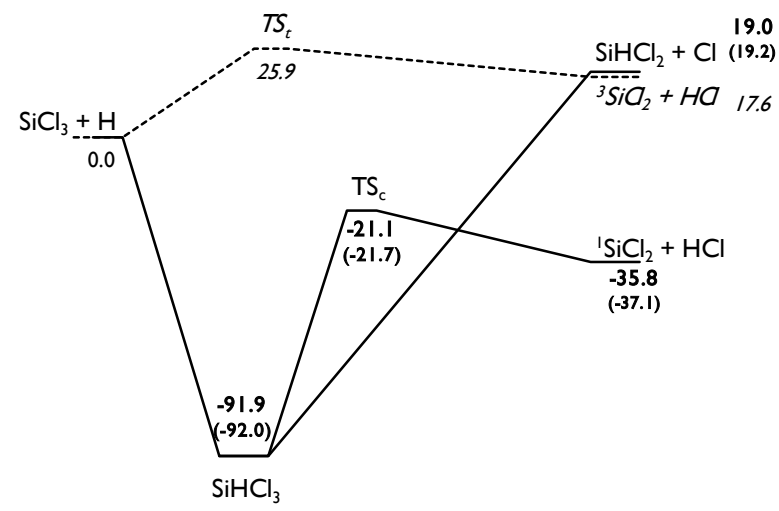

Figure 2: Potential energy diagram for the reaction of $\mathrm{SiCl}_{3}$ with $\mathrm{H}$ atom on the singlet (solid line) and triplet (dashed line) surface based on RCCSD(T)/aug-cc-pVoZ//B2PLYP-D3/aug-cc-pVTZ energies. The energies in brackets are the ZPVE corrected CCSD(T)/cc$\mathrm{pVTZ} / / \mathrm{CASSCF}(8,8) / \mathrm{cc}-\mathrm{pVDZ}$ energies reported by Walch et al. ${ }^{25}$

On the singlet surface, the reaction of $\mathrm{SiCl}_{3}$ with $\mathrm{H}$-atom exhibits a higher complexity. Indeed, the two radicals can recombine (reaction $\mathrm{R}_{7}$ ) to form trichlorosilane $\left(\mathrm{SiHCl}_{3}\right)$ that lies well below the entrance channel. Trichlorosilane can release either a chlorine atom through a unimolecular decomposition reaction (with dichlorosilane $\mathrm{SiHCl}_{2}$ radical as the co-product) or a hydrogen chloride molecule via a 3center concerted elimination transition state (reaction $\mathrm{R}_{8}$ ). The energy of this transition state and of the related set of products $\left({ }^{1} \mathrm{SiCl}_{2}+\mathrm{HCl}\right)$ are located 21.1 and $35.8 \mathrm{kcal} \mathrm{mol}^{-1}$, respectively, below the entrance channel. On the other hand, although the $\mathrm{Cl}$-atom elimination proceeds barrierless, the final 
products $\left({ }^{2} \mathrm{Cl}+{ }^{2} \mathrm{SiHCl}_{2}\right)$ are much higher in energy than the reactants, suggesting that this set of products is unlikely. With trichlorosilane as the initial reactant, the energy barrier of $70.7 \mathrm{kcal} \mathrm{mol}^{-1}$ for the concerted elimination $R_{8}$ is consistent with the activation energy reported by Ravasio et al. ${ }^{5}$ (70.4 kcal mol$\left.{ }^{-1}\right)$ but $3.5 \mathrm{kcal} \mathrm{mol}^{-1}$ larger than the one published by Ge et al..$^{20}\left(67.1 \mathrm{kcal} \mathrm{mol}^{-1}\right)$. Walch and Dateo ${ }^{25}$ obtained an energy barrier of $72.7 \mathrm{kcal} \mathrm{mol}^{-1}$ from MP2-assisted extrapolated CCSD(T)/ccpVTZ//CASSCF $(8,8) / c c-p V D Z$ energies. While this barrier is larger than the one computed herein, it does not include the ZPVE corrections. After these corrections have been taken into account, the corresponding energy barrier for reaction $\mathrm{R}_{8}$ decreases to $70.2 \mathrm{kcal} \mathrm{mol}^{-1}$, which is in excellent agreement with our value. Likewise, the dissociation energies of the $\mathrm{Si}-\mathrm{H}$ and $\mathrm{Si}-\mathrm{Cl}$ bonds computed herein, 91.9 and $110.8 \mathrm{kcal} \mathrm{mol}^{-1}$, are in close agreement with those reported by Ravasio et al. ${ }^{5}$ (93.8 and $\left.110.4 \mathrm{kcal} \mathrm{mol}^{-1}\right)$, Walch and Dateo ${ }^{25}\left(92.0\right.$ and $\left.111.2 \mathrm{kcal} \mathrm{mol}^{-1}\right)$, but larger than the values of Ge et al. $^{20}\left(90.0\right.$ and $\left.106.7 \mathrm{kcal} \mathrm{mol}^{-1}\right)$.

In order to perform a master equation analysis on the singlet potential energy surface with Mesmer, high pressure limit rate constants for the two recombination channels are mandatory. Regarding the addition of the chlorine atom on $\mathrm{SiHCl}_{2}$ radical, the similar value as for $\mathrm{SiCl}_{3}+\mathrm{Cl}$ is adopted (see section on $\mathrm{SiCl}_{4}$ decomposition). Ravasio et al. ${ }^{5}$ and $\mathrm{Ge}$ et al. ${ }^{2}$ have both calculated the $\mathrm{SiCl}_{3}+\mathrm{H}$ recombination rate constants ( $\mathrm{k}_{\infty,-7}$ insert of Figure 3 ), but their values differ with each other by a factor two to three. Therefore, the rate constant has been calculated hereafter. 


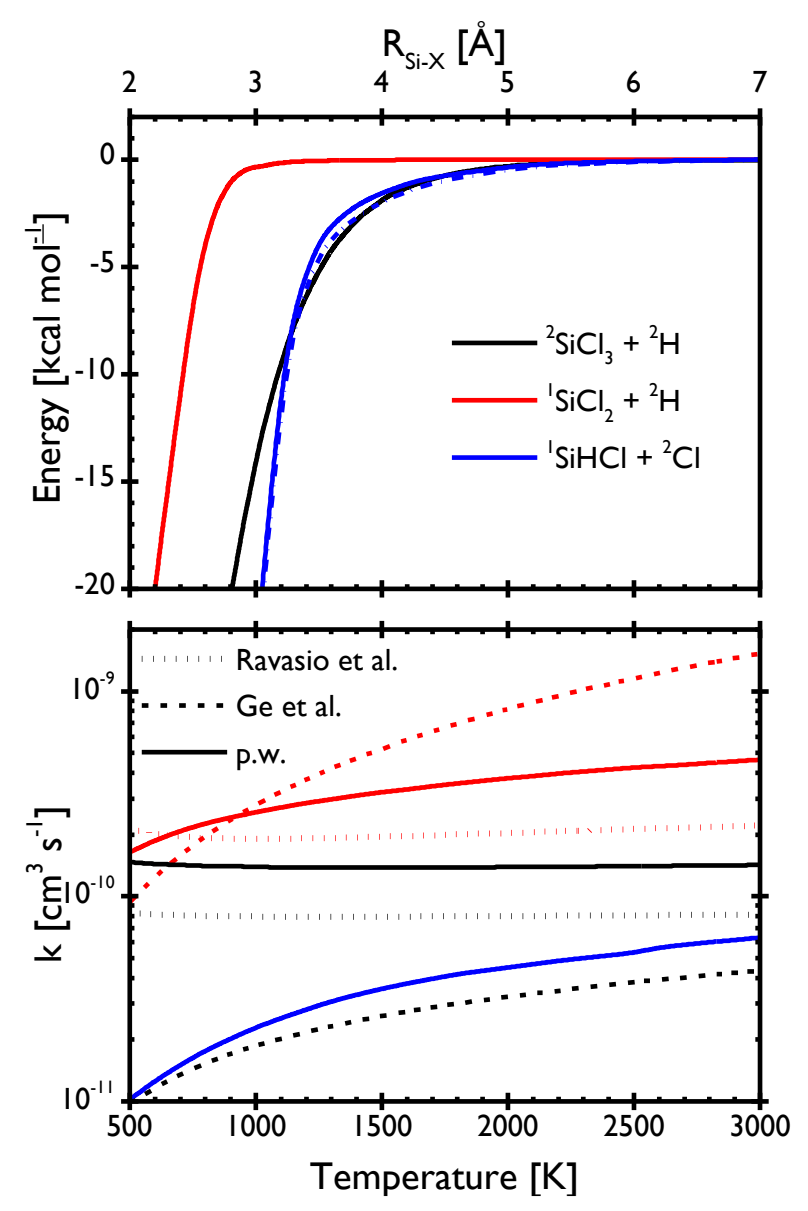

Figure 3: (Upper) Minimum-energy-path potential for the lowest singlet electronic state of ${ }^{2} \mathrm{SiCl}_{3}+{ }^{2} \mathrm{H}$ (black, $\mathrm{R}_{-7}$ ), ${ }^{1} \mathrm{SiCl}_{2}+{ }^{2} \mathrm{H}$ (red, $\mathrm{R}_{-10}$ ) and ${ }^{1} \mathrm{SiHCl}+{ }^{2} \mathrm{Cl}$ (blue, solid and dash-dotted lines with and without spin-orbit coupling, respectively) evaluated at NEVPT2(2,2)/aug-cc-pVœZ level of theory and (lower) Comparison between the herein predicted recombination rate constants (solid lines) and those of Ge et al. ${ }^{2}$ (dashed lines) and Ravasio et al. ${ }^{5}$ (dotted lines) for the three sets of reactants.

The NEVPT2(2,2)/aug-cc-pVœZ calculated interaction energies between $\mathrm{SiCl}_{3}$ and $\mathrm{H}$ in $\mathrm{C}_{3 \mathrm{v}}$ symmetry are displayed in Figure 3 for the lowest singlet electronic state. These energies were calculated based on NEVPT2(2,2)/aug-cc-pVDZ optimized structures, and a method correction (obtained by the difference between the triplet MP2 and the CCSD(T)/aug-cc-pVTZ energies) as introduced by Zhang et al. ${ }^{26}$ was applied as well as the unscaled zero-point vibrational energy. This interaction potential was used to run a VTST analysis, resulting in a recombination rate constant of $\mathrm{k}_{-7, \infty}=8.0710^{13} \mathrm{~T}^{0.01} \mathrm{~cm}^{3} \mathrm{~mol}^{-1} \mathrm{~s}^{-1}$. This value is about $50 \%$ higher than the rate constants of Ravasio et al. ${ }^{5}$ and 4 to 7 times faster than the values of Ge et al. ${ }^{2}$, but are very close to the similar rate constants recommended for alkyl radicals ${ }^{27}$. 


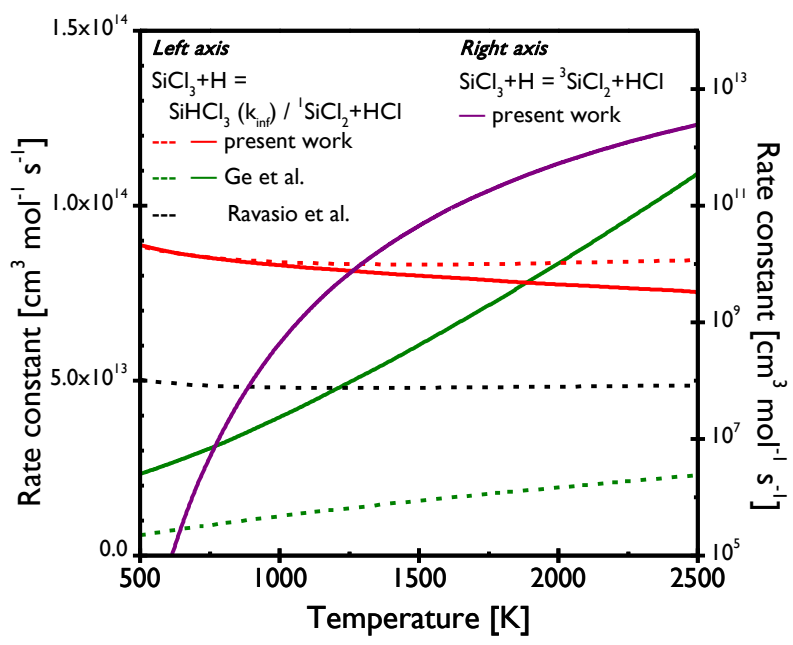

Figure 4: Rate constants for the reaction of $\mathrm{SiCl}_{3}+\mathrm{H}$ on the singlet (left axis; red, green and black lines for the present calculations, the calculations of Ge et al. ${ }^{2}$, and the calculations of Ravasio et al. ${ }^{5}$, respectively) and triplet (right axis; purple line) surface. The solid and dashed lines denote the production of the $\mathrm{SiCl}_{2}+\mathrm{HCl}$ products set $\left(\mathrm{R}_{9 \mathrm{a}}\right.$ and $\left.\mathrm{R}_{9 \mathrm{~b}}\right)$ and the high pressure recombination rate constant $\mathrm{k}_{-10}$, respectively.

The results of the master equation analysis (with argon as the bath gas) are displayed in Figure 4 and Figure 5. Regardless of the pressure and temperature, the main channel for the reaction of $\mathrm{SiCl}_{3}+\mathrm{H}$ is the formation of singlet ${ }^{1} \mathrm{SiCl}_{2}$ and $\mathrm{HCl}\left(\mathrm{R}_{6 \mathrm{a}}\right)$. The corresponding rate constant $\mathrm{k}_{6 \mathrm{a}}$ is pressure independent, and also nearly temperature independent. This rate constant is close to the high pressure limit of the recombination rate constant $\mathrm{k}_{-7, \infty}$, with a slight deviation starting from $\sim 1000 \mathrm{~K}$. The predicted rate constant for this chemically activated reaction is very different both qualitatively and quantitatively from the one reported by Ge et al. ${ }^{2}$ Indeed, according to these authors, the reaction $\mathrm{SiCl}_{3}$ $+\mathrm{H} \rightleftarrows \mathrm{SiCl}_{2}+\mathrm{HCl}\left(\mathrm{R}_{6 \mathrm{a}}\right)$ proceeds through a tight transition state, the energy of which lies $6.2 \mathrm{kcal} \mathrm{mol}^{-}$ ${ }^{1}$ below the reactants. Such a transition state could be identified with the optimization methods employed in this study, but the saddle point exhibited unusual features: the breaking $\mathrm{Si}-\mathrm{Cl}$ bond was shorter than the two others ( 2.060 vs. $2.063 \AA$ ) while the length of the forming $\mathrm{H}-\mathrm{Cl}$ bond was rather large $(2.978 \AA$ ). Moreover, the nature of the reactants related to this saddle point remained elusive, precluding the consideration of this transition state in the present analysis.

When compared to the rate constant of reaction $\mathrm{R}_{1}$, the values of $\mathrm{k}_{6 \mathrm{a}}$ are about three orders of magnitude larger at high temperatures, suggesting that $\mathrm{SiCl}_{3}$ may effectively compete with $\mathrm{SiCl}_{4}$ for $\mathrm{H}$ atom consumption. 


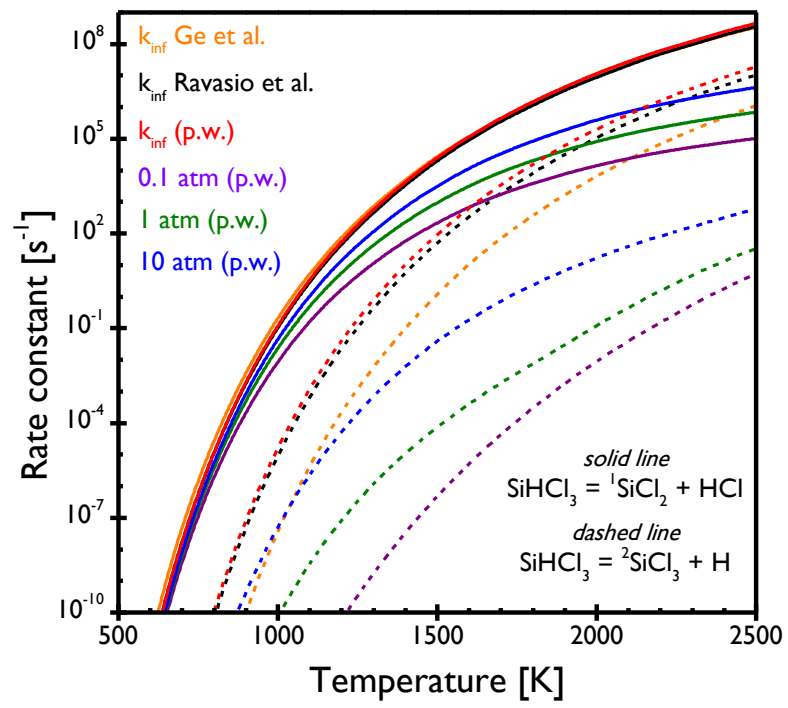

Figure 5: Calculated rate constants for the two decomposition channels $\mathrm{R}_{7}\left(\mathrm{SiHCl}_{3} \rightleftarrows{ }^{1} \mathrm{SiCl}_{2}+\mathrm{HCl}\right.$, solid lines) and $\mathrm{R}_{8}\left(\mathrm{SiHCl}_{3} \rightleftarrows{ }^{2} \mathrm{SiCl}_{3}+\mathrm{H}\right.$, dashed lines) of trichlorosilane $\mathrm{SiHCl}_{3}$ at different pressures in argon. The black and orange lines refer to the rate constants proposed by Ravasio et al. ${ }^{5}$ and $\mathrm{Ge}$ et al. ${ }^{2}$, respectively.

Trichlorosilane decomposition rate constants are displayed in Figure 5. The herein predicted high pressure limits for the two main decomposition channels $\left(\mathrm{R}_{7}\right.$ and $\left.\mathrm{R}_{8}\right)$ are consistent with those reported by Ravasio et al. ${ }^{5}$ The comparison with the values of $\mathrm{Ge}$ et $\mathrm{al}^{2}{ }^{2}$ is more contrasted: whereas a fair agreement is observed for the concerted $\mathrm{HCl}$ elimination channel, the rate constants published by $\mathrm{Ge}$ et $\mathrm{al}^{2}$ are two orders of magnitude slower for the homolytic $\mathrm{Si}-\mathrm{H}$ bond scission. The pressure has a strong influence on the rate constant and this effect increases with the temperature. As such, while, at $1000 \mathrm{~K}$ in argon, the atmospheric pressure rate constant for the elimination reaction is about $12 \%$ of its high pressure limit, this ratio falls down to $4 \%$ at $1500 \mathrm{~K}$. This single example also illustrates that the effect of the pressure cannot be overlooked in developing detailed kinetic models. Temperature and pressure dependent Arrhenius expressions are given in Table 3 for the two $\mathrm{SiHCl}_{3}$ decomposition channels $\mathrm{R}_{7}$ and $\mathrm{R}_{8}$.

\subsubsection{Reactions on the ${ }^{1} \mathrm{SiCl}_{2}+\mathrm{H}$ potential energy surface $\left(\mathrm{R}_{9}-\mathrm{R}_{13}\right)$}

As one of the main intermediate in $\mathrm{SiCl}_{4}$ pyrolysis and oxidation, singlet dichlorosilylene ${ }^{1} \mathrm{SiCl}_{2}$ is expected to react with chain carriers. Its reaction with $\mathrm{H}$-atom has been investigated theoretically by Walch and Dateo ${ }^{28}$, who characterized stationary points with $\operatorname{CASSCF}(7,7) / \mathrm{cc}-\mathrm{pVDZ}$ and refined the energies with $\operatorname{CCSD}(\mathrm{T})$ methods. They found out that two reaction paths are possible and lead to the same set of products, clorosilylidyne $\mathrm{SiCl}$ and hydrogen chloride: a direct abstraction or a recombination to form the dichlorosilane $\mathrm{SiHCl}_{2}$ radical which then decomposes by concerted elimination.

The $\mathrm{SiHCl}_{2}$ potential energy surface proposed by Walch and $\mathrm{Dateo}^{28}$ has been herein reinvestigated and completed with the decomposition channel into $\mathrm{SiHCl}+\mathrm{Cl}$. The RCCSD(T)/aug-cc-pVoZ//B2PLYP- 
D3/aug-cc-pVTZ energies are displayed in Figure 6 and compared to the values of Walch and Dateo. The present surface is very similar to the one published by Walch and Dateo ${ }^{28}$. The minor differences in the stationary point energies can be attributed to the absence of ZPVE correction in the paper of Walch and Dateo ${ }^{28}$. Nonetheless, after applying the ZPVE corrections, a large discrepancy $\left(25.4 \mathrm{kcal} \mathrm{mol}^{-1}\right)$ remains for the energy barrier of the $\mathrm{HCl}$-concerted elimination $\mathrm{R}_{11}$, which cannot be explained by any other missing energy correction term.

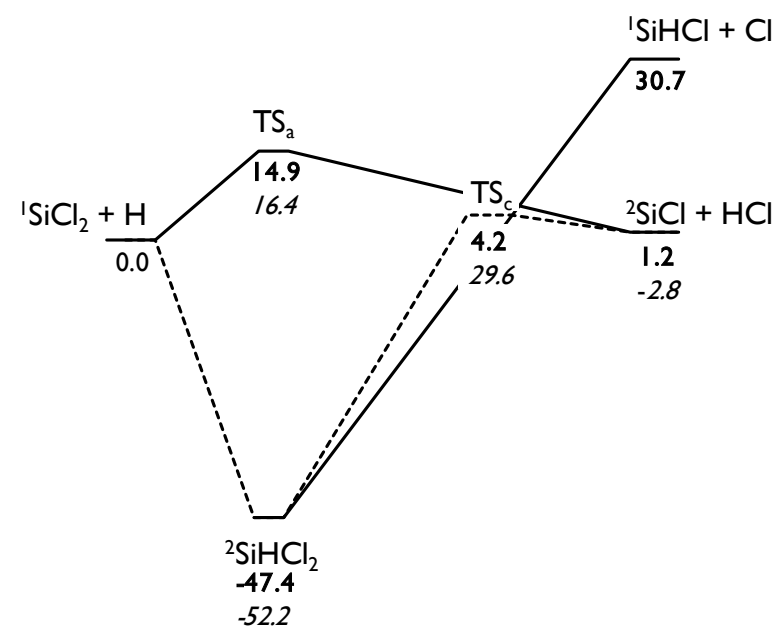

Figure 6: Potential energy diagram for the reaction of singlet $\mathrm{SiCl}_{2}$ with $\mathrm{H}$ atom. Bold values stand for the energies calculated in the present study (RCCSD(T)/aug-cc-pV $\infty$ Z//B2PLYP-D3/aug-ccpVTZ) and italic values are the energies reported by Walch and Dateo (without ZPVE (correction $)^{28}$.

From the $\mathrm{SiHCl}_{3}$ potential energy surface, the rate constant $\mathrm{k}_{9 \mathrm{a}}$ of the direct abstraction channel can be readily obtained from TST. The calculated rate constant is displayed in Figure 7 and compared to the value of Walch and Dateo. Our rate constants are slightly larger than the literature, which may be rationalized by the $2 \mathrm{kcal} \mathrm{mol}^{-1}$ lower energy barrier calculated in the present study.

As already mentioned for the $\mathrm{SiCl}_{3}+\mathrm{H}$ reactions, running a master equation analysis on the $\mathrm{SiHCl}_{2}$ potential energy surface with MESMER requires the high pressure limit recombination rate constants for the two entrance channel (i) $\mathrm{SiCl}_{2}+\mathrm{H}$ and (ii) $\mathrm{SiHCl}+\mathrm{Cl}$. The interaction potentials between the fragments employed to run VTST analysis are displayed in Figure 3. They were obtained from NEVPT2/aug-cc-pVœZ based on B2PLYP-D3/aug-cc-pVTZ geometries. The active space consisted in 3 electrons and 3 orbitals (the $\sigma / \sigma^{*}$ orbitals and the $3 p$ singly occupied of the Si-atom) for channel (i) and of 5 electrons and 5 orbitals (the $\sigma / \sigma^{*}$ orbitals, the single occupied $3 p$ orbital of the Si-atom and the two $3 p$ orbitals of the $\mathrm{Cl}$-atom) for channel (ii). 


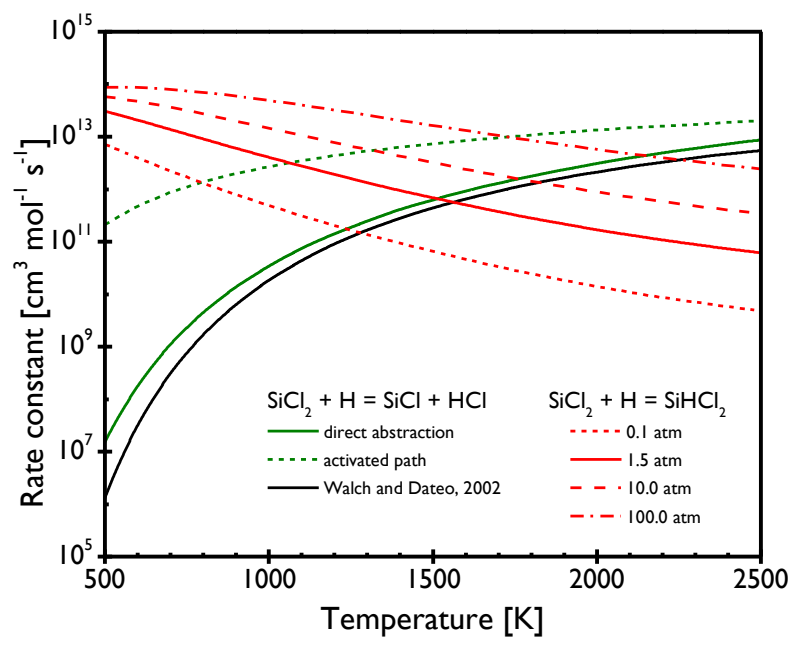

Figure 7: Rate constants for the reaction of singlet dichlorosilylene with $\mathrm{H}$-atom. The green and black solid lines denotes the direct abstraction path as calculated in the present work and by Walch and $\mathrm{Dateo}^{28}$. The dashed green line displays the contribution of the chemically activated reaction to the $\mathrm{SiCl}+\mathrm{HCl}$ set of products. The red lines illustrate the effect of the pressure on the formation of the dichlorosilane $\mathrm{SiHCl}_{2}$ radical.

In the case of channel (ii), the stabilization energy resulting from the spin-orbit coupling has been computed using NEVPT2 method with the aug-cc-pVTZ basis set. This predicted stabilization energy is strongly geometry dependent ${ }^{29}$ and decreases as the halogen atom moves closer to the $\mathrm{SiHCl}$ fragment. As a consequence, the spin-orbit coupling makes the interaction potential less attractive as illustrated by the comparison between the potentials with (dashed line) and without (dotted line) this correction.

As expected, the interaction potentials are shorter ranged for the $\mathrm{H}$-atom than the $\mathrm{Cl}$-atom because of the larger radius of the halogen atom. Moreover, whereas the $\mathrm{SiHCl}-\mathrm{Cl}$ potential is observed to be more attractive right before the minimum interaction distance $\left(\mathrm{R}_{\min } \sim 5 \AA\right)$ than the $\mathrm{SiCl}_{2}-\mathrm{H}$ potential $\left(\mathrm{R}_{\text {min }}\right.$ $\sim 3.5 \AA$ ), this latter shows a higher attractiveness at mid-range interactions distances (relative to their respective $R_{\min }$ ).

The recombination rate constants derived from the interaction potentials of Figure 3 are displayed in the insert of this figure. The capture rate constants for the $\mathrm{H}$ atom are about one order of magnitude larger than those for the capture of the halogen atom. It can be observed that the present $\mathrm{SiCl}_{2}+\mathrm{H}$ recombination rate constants are intermediate between the values reported by Ge et al. and Ravasio et al., and comparable to those previously calculated for $\mathrm{SiCl}_{3}+\mathrm{H}$.

These high pressure recombination rate constant have been supplied to MESMER along with the PES of Figure 6 to derive the temperature and pressure dependent rate constants for the decomposition of the dichlorosilane $\mathrm{SiHCl}_{2}$ radical and the reaction of singlet $\mathrm{SiCl}_{2}$ with $\mathrm{H}$-atoms. For the reaction of interest, i.e. $\mathrm{SiCl}_{2}+\mathrm{H}=\mathrm{SiCl}+\mathrm{HCl}\left(\mathrm{R}_{9}\right)$, the rate constant of the chemically activated path is found, like the direct abstraction channel, to be pressure independent. From Figure 7, it can however be observed that the rate constant of the direct path $\mathrm{k}_{9 \mathrm{a}}$ is several orders of magnitude lower than the activated path $\mathrm{k}_{9 \mathrm{~b}}$, 
which is to be related to the barrierless entrance channel in the second case. Reaction $\mathrm{R}_{-9}$ is nevertheless competing with the association reaction producing $\mathrm{SiHCl}_{2}\left(\mathrm{R}_{-10}\right)$, and this competition strongly depends on the pressure. Indeed, whereas at pressure as low as 0.1 atm reaction $\mathrm{R}-9$ overtakes the reaction $\mathrm{R}_{-10}$ at temperatures above $800 \mathrm{~K}$, the turning temperature increases to $1100 \mathrm{~K}$ around atmospheric pressure and keeps increasing to reach $1700 \mathrm{~K}$ at $100 \mathrm{~atm}$. Therefore, as the pressure increases, the recombination path is favored over the "abstraction-like" path, which is consistent with Le Châtelier's principle.

Figure 8 shows the predicted rate constants for the two main decomposition channels of $\mathrm{SiHCl}_{2}$, namely $\mathrm{R}_{10}$ and $\mathrm{R}_{11}$. The present high-pressure limit rate constant $\mathrm{k}_{10, \infty}$ is in excellent agreement with the reported values of Ravasio et al. and $\mathrm{Ge}$ et al. The effect of the pressure on the individual rate constants is rather pronounced. Indeed, for reaction $\mathrm{R}_{10}$, the $1000 \mathrm{~K}$ rate constant at $1.5 \mathrm{~atm}$ is only about $1 \%$ of its high pressure limit value, and this ratio falls down to $1 \%$ at $1500 \mathrm{~K}$ and $1.5 \mathrm{~atm}$. These ratios are even lower for the second channel $\mathrm{R}_{11}$.

Despite that the energy barriers of these two reactions are relatively similar (Figure 6), the reaction $R_{10}$ strongly overtakes reaction $\mathrm{R}_{11}$. For example, at $1000 \mathrm{~K}$ and $1.5 \mathrm{~atm}, \mathrm{k}_{10}$ is about 5000 times larger than $\mathrm{k}_{11}$. As the pressure and temperature increase, this ratio gets smaller but never falls below the order of magnitude. Although the loss of a $\mathrm{Cl}$-atom was included in the $\mathrm{ME}$ analysis, the predicted rate constants were calculated negligible and are thus neither shown nor further considered in the present study.

The sensitivity of the predicted rate constants to some of the Mesmer input parameters, namely the Lennard-Jones collision diameter, the energy-down collision model, and the high pressure limit recombination rate constant $\mathrm{k}_{\mathrm{SiCl} 2+\mathrm{H}}$, has been carried out and first-order sensitivity coefficients determined. The rate constant $\mathrm{k}_{9 \mathrm{~b}}$ was observed to be not sensitive to any of the three parameters. On the other hand, $\mathrm{k}_{10}$ and $\mathrm{k}_{11}$ are at first sensitive to the energy model employed $\left(\mathrm{S}_{\mathrm{E}, 10} \sim 1.4\right.$ and $\left.\mathrm{S}_{\mathrm{E}, 11} \sim 3.2\right)$ and then to the collision diameter adopted for $\operatorname{SiHCl}_{2}\left(\mathrm{~S}_{\sigma, 10} \sim 1.0\right.$ and $\left.\mathrm{S}_{\sigma, 11} \sim 2.0\right)$. Surprisingly, $\mathrm{k}_{10}$ is weakly sensitive $\left(S_{k, 10} \sim 0.2\right)$ to the value of $k_{-10}$ used for the Inverse Laplace Transform procedure of Mesmer, unlike $\mathrm{k}_{11}$ which exhibits a large negative sensitivity coefficient to this parameter $\left(\mathrm{S}_{\mathrm{k}, 11} \sim-1.5\right)$. 


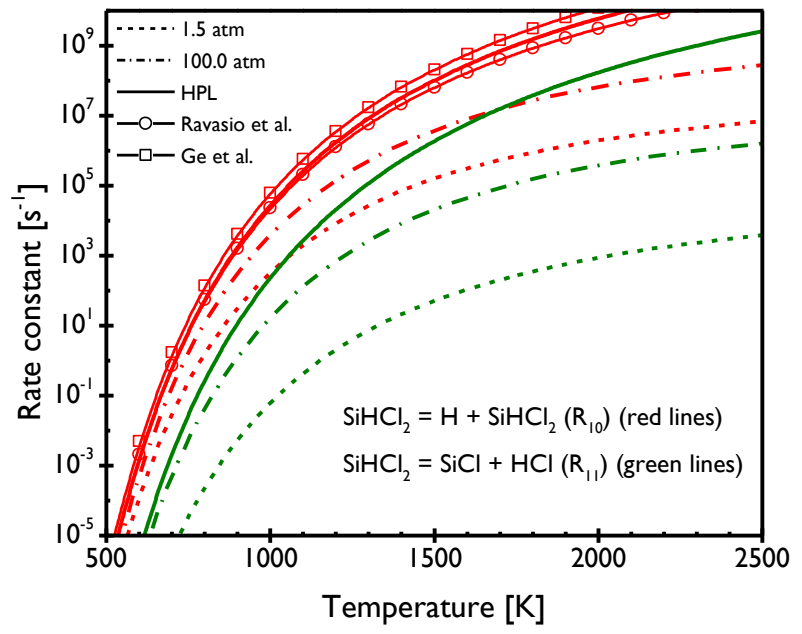

Figure 8: Rate constants in argon of the two main decomposition channels of $\mathrm{SiHCl}_{2}\left(\mathrm{R}_{10}\right.$, red lines, and $\mathrm{R}_{11}$, greens lines) at different pressures (1.5 atm, $100 \mathrm{~atm}$, and high pressure limit). The lines with open squares and circles display the high pressure limits of reaction $\mathrm{R}_{10}$ reported by Ravasio et al. ${ }^{5}$ and $\mathrm{Ge}$ et al. ${ }^{2}$, respectively

\subsubsection{Decomposition of $\mathrm{SiCl}_{4}\left(\mathrm{R}_{2}\right)$}

The thermal decomposition of $\mathrm{SiCl}_{4}\left(\mathrm{R}_{2}\right)$ has been investigated experimentally in previous studies. Using diluted $\mathrm{SiCl}_{4} / \mathrm{H}_{2} / \mathrm{Ar}$ mixtures and neglecting secondary chemistry, Catoire et al. ${ }^{30}$ could infer apparent rate constants for the reaction $\mathrm{R}_{2}$ by monitoring the early production of $\mathrm{H}$ atoms, according to the sequence:

$$
\begin{array}{ll}
\mathrm{R}_{2} & \mathrm{SiCl}_{4} \rightleftarrows \mathrm{SiCl}_{3}+\mathrm{Cl} \\
\mathrm{R}_{14} & \mathrm{H}_{2}+\mathrm{Cl} \rightleftarrows \mathrm{HCl}+\mathrm{H}
\end{array}
$$

A few years later, Kunz et al. ${ }^{4}$ could extract an apparent rate constant by following the formation of $\mathrm{Si}$ and $\mathrm{Cl}$ atoms in $\mathrm{SiCl}_{4} / \mathrm{Ar}$ mixtures. The use of highly diluted mixtures (a few ppm of $\mathrm{SiCl}_{4}$ ) prevented parasite absorption of the fuel while minoring secondary chemistry. Both studies assumed that the experimental conditions (high temperature, around atmospheric pressure) were representative of the low pressure regime of this reaction and therefore have reported second order rate constants. Although both series of measurements were performed in the same temperature (1500-2400 K) and pressure range (1.01.6 bar), the recommended rate constants differ by nearly an order of magnitude (Figure 9). Indeed, the values of Catoire et al. ${ }^{30}$ are extremely close to the lower bound of the uncertainty associated to the rate constant proposed by Kunz and Roth. Along with this discrepancy, none of the two mentioned studies attempted to tackle or discuss the pressure and temperature dependency of this rate constant outside of the thermodynamic conditions investigated.

In the kinetic models proposed by Ge et al. ${ }^{2}$ and Ravasio et al. ${ }^{5}$, the thermal decomposition of $\mathrm{SiCl}_{4}$ has been included and therefore rate constants have been proposed. In both studies, the high pressure limit rate constants were derived from VTST calculations as the reaction proceeds barrierless towards the 
products. Rovibrational and energetic properties were obtained by different methods between the two studies (CR-CC(2,3)/cc-pVTZ//MP2/cc-pVDZ for Ge et al. ; UB3LYP/6-31+G(d,p) with final energies scaled by the $\operatorname{CCSD}(\mathrm{T}) / \mathrm{cc}-\mathrm{pV}(\mathrm{D}, \mathrm{T}) \mathrm{Z} / / \mathrm{B} 3 \mathrm{LYP} / 6-31+\mathrm{G}(\mathrm{d}, \mathrm{p})$ heat of reaction for Ravasio et al.), but resulted in final rate constants that are in close agreement with each other. These theoretical rate constants are compared in Figure 9 to the experimental values of Catoire et al. ${ }^{30}$ and Kunz and Roth ${ }^{4}$. It appears, from the discrepancy between the theoretical high pressure limits and the experimental values of Catoire et al., that reaction $\mathrm{R}_{2}$ must exhibit a significant pressure dependence, especially at high temperature, as suggested by the increase of the ratio $\mathrm{k}_{\infty} / \mathrm{k}_{\text {exp }}$. Moreover, Figure 9 would suggest that the value recommended by Kunz and Roth is overestimated at low temperatures $(<1700 \mathrm{~K})$ since their rate constants are even faster than the theoretical high pressure limit.

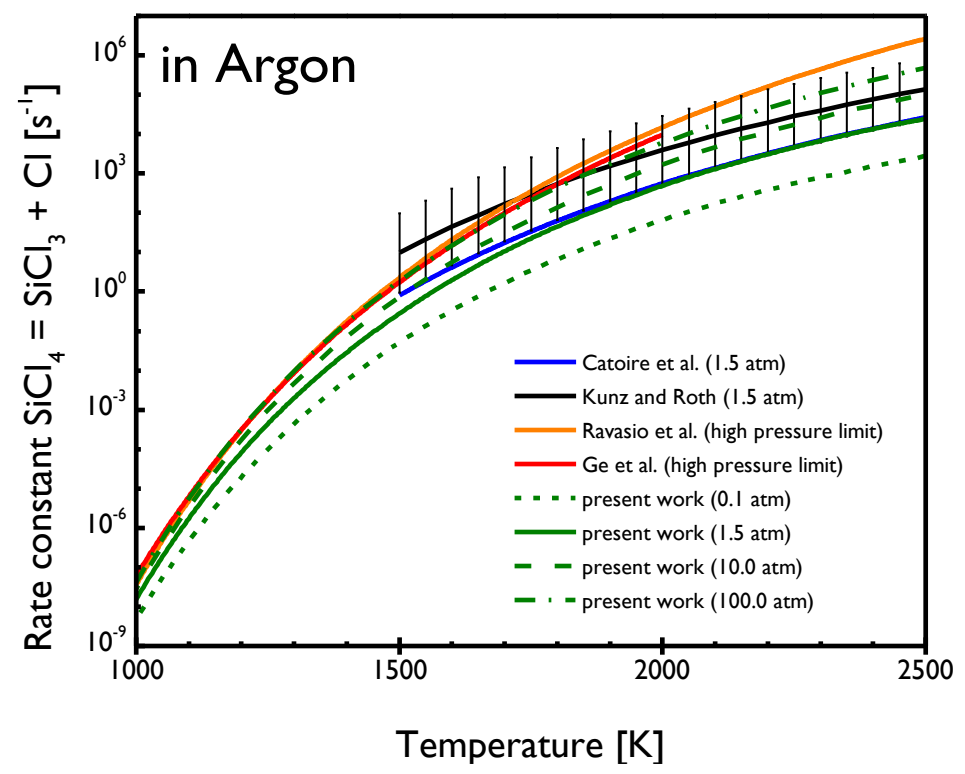

Figure 9: Rate constant of the decomposition reaction of silicon tetrachloride $\left(\mathrm{R}_{2}\right)$ : comparison between values from the literature and the present predictions.

From the above observations, it is evident that the thermal decomposition of $\mathrm{SiCl}_{4}$ deserves further investigation in order to settle the apparent experimental inconsistency and access both the temperature and pressure dependency.

In the present study, we have employed the recombination rate constant $\mathrm{k}_{-2, \infty}$ published by Ravasio et al. $^{5}\left(k_{\infty,-2}=9.0010^{12} T^{0.23} e^{203 / T}\right.$, in $\left.\mathrm{cm}^{3} \mathrm{~mol}^{-1} \mathrm{~s}^{-1}\right)$ as input parameter for the Inverse Laplace Transform procedure of Mesmer to obtain the microcanonical rate constants. The rate constant of Ravasio et al. ${ }^{5}$ was preferred over the one of Ge et al. ${ }^{2}$ because it is in closer agreement with the recommended rate constant of Kumaran et al. ${ }^{31}$ for the closely related $\mathrm{CCl}_{3}+\mathrm{Cl}$ system. The rovibrational and energetics properties of reactants and products were obtained at the RCCSD(T)/augcc-pVœZ//B2PLYP-D3/aug-cc-pVTZ level of theory (see section 3.1.1). The rate constants obtained by this procedure in argon as the bath gas are displayed in Figure 9. A strong pressure dependence is 
predicted by the master equation analysis. Whereas the rate constants appear to approach the high pressure limit even at $0.1 \mathrm{~atm}$ around $1000 \mathrm{~K}$, an unambiguous fall-off regime is observed between 1000 and $2500 \mathrm{~K}$. The $1.5 \mathrm{~atm}$ predicted rate constants agree well with the experimental values of Catoire et al., thus confirm the surprisingly elevated rate constants of Kunz and Roth. The $\mathrm{k}_{2}(\mathrm{~T}, \mathrm{P})$ data in argon were turned into a Troe formalism expression, and Chaperon efficiencies for $\mathrm{N}_{2}, \mathrm{He}$, and $\mathrm{SiCl}_{4}$ were determined by running the ME analysis in these bath gases. The temperature and pressure dependent rate constant $\mathrm{k}_{2}$ in the Troe formalism is given in Table 3 .

The sensitivity of $\mathrm{k}_{2}$ with respect to four of the Mesmer input parameters was assessed. These parameters consisted on the recombination rate constant, the heat of the reaction, the $\mathrm{SiCl}_{4}$ collision diameter, and the collision energy model. Sensitivity coefficients were calculated at two different temperatures (1000 and $1500 \mathrm{~K}$ ) and pressures (1 and $10 \mathrm{~atm}$ ) and are given in the Supplementary Materials. The final rate constant is weakly sensitive to the heat of reaction or Bond Dissociation Energy, although a decrease of $1 \mathrm{kcal} \mathrm{mol}^{-1}$ of the BDE would result in a slightly higher ( 20\%) decomposition rate constant. Increasing the recombination rate constant $\mathrm{k}_{-2, \infty}$ necessarily results in an increase of the final value of $\mathrm{k}_{2}$, however mitigated by the ME analysis: an increase of a factor 2 of $\mathrm{k}_{-2, \infty}$ leads to an increase of 30 to $60 \%$ in $\mathrm{k}_{2}$, depending on the temperature and pressure. Like the previous reactions, the final values of $k_{2}$ are mainly sensitive to the collision model, including the collision diameter and the energy transfer, with sensitivity coefficients close to unity. As the temperature increases, the promoting effect of increasing $\langle E\rangle_{\text {down }}$ and $\sigma_{\mathrm{SiCl} 4}$ is strengthened whereas it is weakened by an increase of the pressure. Based on these observations, and considering the uncertainties on the ME parameters, the reported $\mathrm{k}_{2}(\mathrm{~T}, \mathrm{P})$ values can be prescribed an uncertainty factor of two to three.

\subsubsection{Reaction $\mathrm{H}_{2}+\mathrm{Cl}\left(\mathrm{R}_{14}\right)$}

The reaction of chlorine atoms with hydrogen $\mathrm{H}_{2}$ is expected to be a kinetic governing step for the $\mathrm{H}$ atom profiles of the second series of experiments $\left(\mathrm{SiCl}_{4} / \mathrm{H}_{2}\right.$ mixtures). This reaction has been the focus of several experimental studies ${ }^{32-35}$ in which $\mathrm{Cl}$-atoms were produced in-situ and their consumption by reaction with $\mathrm{H}_{2}$ monitored by Chlorine ARAS. Figure 10 shows that, when combined, all the experimental data span a large temperature range, but also exhibit a large scattering. Theoretical rate constants have also been published. Mielke et al. ${ }^{36}$ derived a rate constant from the full potential energy surface of the $\mathrm{H}_{2} \mathrm{Cl}$ system which is in fair agreement with the low to intermediate temperature data but is significantly lower than the higher temperature data. Along with Si related reactions, Ge et al. ${ }^{2}$ proposed as well a rate constant for the reaction of $\mathrm{H}_{2}$ with $\mathrm{Cl}$-atom which is much faster than the high temperature data of Kumaran et al. ${ }^{35}$

To settle the disagreement between the various experimental data sets and the theoretical values, the energetics of the reaction has been calculated with several methods of various accuracies. The resulting energy barriers and the heats of reaction at $0 \mathrm{~K}$ are provided in Table 2 . With the exception of the 
RCCSD(T)/aug-cc-pVœZ//M06-2x-D3/aug-cc-pVDZ results, all methods are consistent with each other, yielding a reaction energy barrier of $\sim 5.5 \mathrm{kcal} \mathrm{mol}^{-1}$, which is also close from the reported barrier of Ge et al. ${ }^{20}$ The consistency for the heat of reaction is even better, and the average value $\left(1.08 \mathrm{kcal} \mathrm{mol}^{-}\right.$ ${ }^{1}$ ) is in excellent agreement with the heat of reaction calculated from the Active Thermochemical Tables ${ }^{37}$ but lower than the one calculated by Ge et al.

Table 2: Energy barrier $\Delta \mathrm{E}^{\#}$ and heat of reaction $\Delta \mathrm{H}^{0 \mathrm{~K}}$ for the $\mathrm{H}_{2}+\mathrm{Cl} \rightleftarrows \mathrm{HCl}+\mathrm{H}$ reaction $\left(\mathrm{R}_{14}\right)$ calculated with different methods (all energies are in $\mathrm{kcal} \mathrm{mol}^{-1}$ ).

\begin{tabular}{|c|c|c|}
\hline Method & $\Delta \mathbf{E}^{\#}$ & $\Delta \mathbf{H}^{0 \mathrm{~K}}$ \\
\hline RCCSD(T)/aug-cc-pVœZ//M06-2x-D3/aug-cc-pVDZ & 4.95 & 1.05 \\
\hline RCCSD(T)/aug-cc-pVœZ//B2PLYP-D3/aug-cc-pVDZ & 5.51 & 1.07 \\
\hline RCCSD(T)/aug-cc-pVœZ//B2PLYP-D3/aug-cc-pVTZ & 5.42 & 1.02 \\
\hline RCCSD(T)-F12/cc-pVœZ//B2PLYP-D3/aug-cc-pVTZ & 5.49 & 1.13 \\
\hline $\operatorname{RCCSD}(\mathrm{T}) /$ aug-cc-pV $\infty \mathrm{Z} / / \mathrm{CCSD}(\mathrm{T}) / \mathrm{cc}-\mathrm{pVT}(+\mathrm{d}) \mathrm{Z}$ & 5.53 & 1.12 \\
\hline CCSD(T)/aug-cc-pVTZ//MP2/aug-cc-pVDZ ${ }^{20}$ & 5.40 & 1.60 \\
\hline Active Thermochemical Tables ${ }^{37}$ & & 1.08 \\
\hline
\end{tabular}

The rovibrational properties and energetics were employed to calculate the reaction rate constants within the RRHO framework, inclusive an asymmetric Eckart tunneling correction. The rate constants obtained are displayed in Figure 10 as dashed lines. As it could be expected from the consistency in the calculated energy barriers, the predicted rate constant is weakly dependent on the method employed to optimize the reactants and transition state geometries. While a fair agreement is obtained with the experimental data at low temperatures, the predictions are about a factor two larger than the high temperature measurements of Kumaran et al., though lower than the predictions of Ge et al. In order to refine the calculated rate constants, the first order anharmonicity constants of the TS and the reactants have been introduced in the TST analysis, without modifying the reaction energy barrier. This "anharmonic" rate constant is denoted as the red solid line in Figure 10. It can be seen that this correction strongly enhances the agreement with the moderate and high temperature data while it does not affect the predictions below $500 \mathrm{~K}$. 


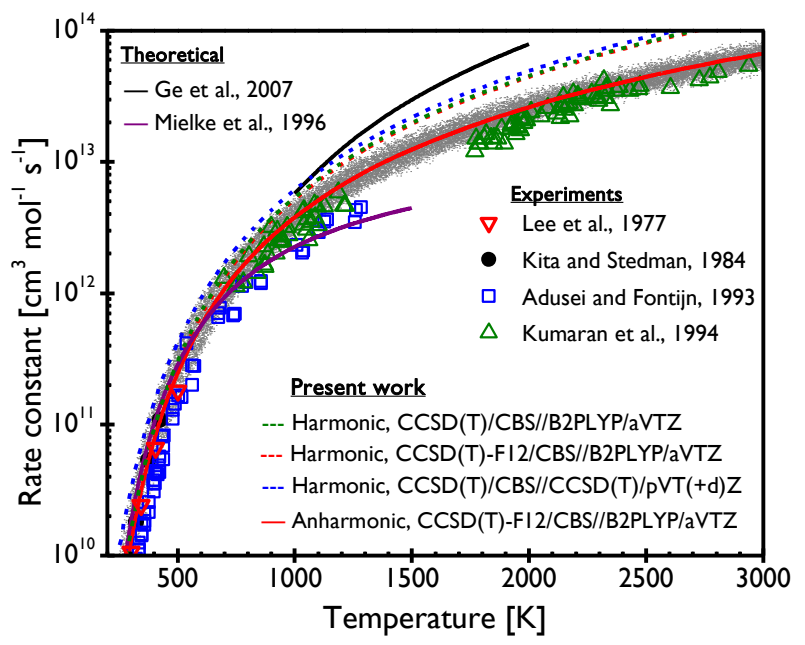

Figure 10: Experimental measurements and theoretical predictions for the rate constant of reaction $\mathrm{R}_{14}$ $\mathrm{H}_{2}+\mathrm{Cl} \rightleftarrows \mathrm{HCl}+\mathrm{H}$

A sensitivity analysis to the calculated parameters has finally been carried out in a similar fashion as explained above for the $\mathrm{SiCl}_{4}+\mathrm{H}$. The same perturbation factors have been applied to the fundamental frequencies and the anharmonic constants. The dot-cloud in Figure 10 displays the results of this analysis. 
Table 3: Rate constants calculated in the present study and implemented in the detailed kinetic model. Rate constants are expressed in $\mathrm{s}^{-1}$ (unimolecular reactions) or $\mathrm{cm}^{3} \mathrm{~mol}^{-1} \mathrm{~s}^{-1}$ (bimolecular reactions and low pressure limits).

\begin{tabular}{|c|c|c|c|}
\hline \# & Reaction & Rate constant & Reference \\
\hline 1 & $\mathrm{SiCl}_{4}+\mathrm{H} \rightleftarrows \mathrm{SiCl}_{3}+\mathrm{HCl}$ & $k=1.1610^{9} \times T^{1.70} \times \exp (-9266 / T)$ & this work \\
\hline 2 & $\mathrm{SiCl}_{4}(+\mathrm{M}) \rightleftarrows \mathrm{SiCl}_{3}+\mathrm{Cl}(+\mathrm{M})$ & $\begin{array}{l}k_{\infty}=1.4110^{22} \times T^{-1.61} \times \exp (-56634 / T) \\
k_{0}=2.1010^{35} \times T^{-4.67} \times \exp (-52809 / T) \\
F_{c}=0.611 \times \exp (-T / 1409)+0.389 \times \\
\exp (-T / 79)+\exp (-212034 / T) \\
\alpha_{A r}=1.00, \alpha_{H e}=2.00, \alpha_{N_{2}}=1.55, \alpha_{S_{i C l}}=5.15\end{array}$ & this work \\
\hline 3 & $\mathrm{SiCl}_{3}+\mathrm{M} \rightleftarrows{ }^{1} \mathrm{SiCl}_{2}+\mathrm{Cl}+\mathrm{M}$ & $k=4.6010^{15} \times \exp (-32815 / T)$ & Kunz and Roth ${ }^{4}$ \\
\hline 4 & ${ }^{1} \mathrm{SiCl}_{2}+\mathrm{M} \rightleftarrows \mathrm{SiCl}+\mathrm{Cl}+\mathrm{M}$ & $k=5.4010^{15} \times \exp (-39300 / T)$ & Kunz and Roth ${ }^{4}$ \\
\hline 5 & $\mathrm{SiCl}_{4}+\mathrm{H} \rightleftarrows \mathrm{SiHCl}_{3}+\mathrm{Cl}$ & $k=5.1510^{6} \times T^{1.87} \times \exp (-26354 / T)$ & this work \\
\hline $6 a$ & $\mathrm{SiCl}_{3}+\mathrm{H} \rightleftarrows{ }^{1} \mathrm{SiCl}_{2}+\mathrm{HCl}$ & $k=1.8410^{14} \times T^{-0.11} \times \exp (-17 / T)$ & this work \\
\hline $6 b$ & $\mathrm{SiCl}_{3}+\mathrm{H} \rightleftarrows{ }^{3} \mathrm{SiCl}_{2}+\mathrm{HCl}$ & $k=1.0010^{10} \times T^{1.35} \times \exp (-12596 / T)$ & this work \\
\hline 7 & $\mathrm{SiHCl}_{3} \rightleftarrows \mathrm{SiCl}_{3}+\mathrm{H}$ & $\begin{array}{l}k_{0.01 \mathrm{~atm}}=6.7410^{7} \times T^{-0.01} \times \exp (-44762 / T) \\
k_{0.1 \mathrm{~atm}}=7.6510^{21} \times T^{-3.73} \times \exp (-46593 / T) \\
k_{1 \mathrm{~atm}}=3.6810^{33} \times T^{-6.60} \times \exp (-48850 / T) \\
k_{10 \mathrm{~atm}}=1.0510^{37} \times T^{-7.05} \times \exp (-50204) \\
k_{100 \mathrm{~atm}}=7.4110^{33} \times T^{-5.73} \times \exp (-50269)\end{array}$ & this work \\
\hline 8 & $\begin{array}{l}\mathrm{SiHCl}_{3} \\
(+\mathrm{M})\end{array}(+\mathrm{M}) \rightleftarrows{ }^{1} \mathrm{SiCl}_{2}+\mathrm{HCl}$ & $\begin{array}{l}k_{\infty}=1.0610^{11} \times T^{1.01} \times \exp (-35547 / T) \\
k_{0}=1.9610^{50} \times T^{-9.37} \times \exp (-78174 / T) \\
F_{c}=0.204 \times \exp (-T / 3577)+0.796 \times \\
\exp (-T / 230)+\exp (-8067 / T) \\
\alpha_{A r}=1.00, \alpha_{H e}=1.54, \alpha_{N_{2}}=3.75, \alpha_{S_{i C l_{4}}}=5.60\end{array}$ & this work \\
\hline $9 \mathrm{a}$ & ${ }^{1} \mathrm{SiCl}_{2}+\mathrm{H} \rightleftarrows \mathrm{SiCl}+\mathrm{HCl}$ & $k=5.4110^{6} \times T^{2.14} \times \exp (-6035 / T)$ & this work \\
\hline $9 b$ & ${ }^{1} \mathrm{SiCl}_{2}+\mathrm{H} \rightleftarrows \mathrm{SiCl}+\mathrm{HCl}$ & $k=2.3310^{10} \times T^{0.96} \times \exp (-1864 / T)$ & this work \\
\hline 10 & $\mathrm{SiHCl}_{2}(+\mathrm{M}) \rightleftarrows{ }^{1} \mathrm{SiCl}_{2}+\mathrm{H}(+\mathrm{M})$ & $\begin{array}{l}k_{\infty}=3.4610^{16} \times T^{-0.40} \times \exp (-25004 / T) \\
k_{0}=1.8110^{37} \times T^{-6.07} \times \exp (-25732 / T) \\
F_{c}=0.162 \times \exp (-T / 18823)+0.838 \times \\
\exp (-T / 50)+\exp (-9172 / T) \\
\alpha_{A r}=1.00, \alpha_{H e}=1.54, \alpha_{N_{2}}=3.75, \alpha_{S_{i C l_{4}}}=5.60\end{array}$ & this work \\
\hline 11 & $\mathrm{SiHCl}_{2} \rightleftarrows \mathrm{SiCl}+\mathrm{HCl}$ & $\begin{array}{l}k_{0.1 \mathrm{~atm}}=1.7110^{7} \times T^{-0.15} \times \exp (-23405 / T) \\
k_{1 \mathrm{~atm}}=3.0010^{28} \times T^{-5.93} \times \exp (-27306 / T) \\
k_{10 \mathrm{~atm}}=6.9110^{32} \times T^{-6.80} \times \exp (-28371 / T) \\
k_{100 \mathrm{~atm}}=5.9510^{34} \times T^{-6.90} \times \exp (-29543 / T)\end{array}$ & this work \\
\hline 12 & $\mathrm{SiHCl}+\mathrm{Cl} \rightleftarrows{ }^{1} \mathrm{SiCl}_{2}+\mathrm{H}$ & $k=1.3210^{11} \times T^{0.69} \times \exp (-381 / T)$ & this work \\
\hline 13 & $\mathrm{SiHCl}+\mathrm{Cl} \rightleftarrows \mathrm{SiCl}+\mathrm{HCl}$ & $k=8.0810^{8} \times T^{1.16} \times \exp (+140 / T)$ & this work \\
\hline 14 & $\mathrm{H}_{2}+\mathrm{Cl} \rightleftarrows \mathrm{HCl}+\mathrm{H}$ & $k=1.2710^{8} \times T^{1.71} \times \exp (-1518 / T)$ & this work \\
\hline
\end{tabular}

\subsection{Comparisons between experimental data and an updated detailed chemical model}

3.2.1. Updated detailed chemical kinetic model 
The detailed chemical kinetic model built for this study consists of 124 reactions involving 51 species. The model is provided in the Supplementary Materials. $\mathrm{The}_{\mathrm{SiH}} \mathrm{Cl}_{\mathrm{y}}$ reaction subset was assembled from the reactions theoretically investigated in this study and complementary reactions were adopted from the work of Ge et al. ${ }^{2}$ The silane subset published by Mével et al. ${ }^{38}$ was also included whereas the $\mathrm{C}_{0^{-}}$ $\mathrm{C}_{2}$ pyrolysis submodel was adopted from the Aramco-Mech mechanism ${ }^{39}$ in order to describe the hydrogen and carbon chemistry (mandatory for the experiments with $\mathrm{C}_{2} \mathrm{H}_{5} \mathrm{I}$ ). Recombination reactions for $\mathrm{I}$ and $\mathrm{Cl}$ atoms with other atom/radical species were also implemented.

Regarding the decomposition of ethyl iodine, the rate constants proposed by Varga et al. ${ }^{40}$ for both the homolytic decomposition $\left(\mathrm{C}_{2} \mathrm{H}_{5} \mathrm{I} \rightleftarrows \mathrm{C}_{2} \mathrm{H}_{5}+\mathrm{I}\right.$, R86) and concerted elimination $\left(\mathrm{C}_{2} \mathrm{H}_{5} \mathrm{I} \rightleftarrows \mathrm{C}_{2} \mathrm{H}_{4}+\mathrm{HI}, \mathrm{R} 87\right)$ were preferred over the values of Yang et al. ${ }^{41}$ and Kumaran et al. ${ }^{42}$. Indeed, the rate constants recommended by Varga are for pressures around atmospheric pressure with argon as the bath gas, whereas the two other cited studies were carried at much lower pressures and in krypton.

\subsection{2. $\mathrm{SiCl}_{4} / \mathrm{C}_{2} \mathrm{H}_{5} \mathrm{I}$ mixtures}

\subsubsection{Mixture composition}

As mentioned in the experimental section, the absorbance of $\mathrm{SiCl}_{4} / \mathrm{C}_{2} \mathrm{H}_{5} \mathrm{I}$ has been monitored. Behind the reflected shock-wave, $\mathrm{C}_{2} \mathrm{H}_{5} \mathrm{I}$ decomposes to a large extent ( $\sim 80 \%$ according to the rate constants of Varga et al.) into an ethyl radical, which further releases an $\mathrm{H}$-atom. Therefore, it could be expected to observe an $\mathrm{H}$-atom concentration roughly equal to $80 \%$ of the initial $\mathrm{C}_{2} \mathrm{H}_{5} \mathrm{I}$ concentration. Nevertheless, experimental measurements are in conflict with this assumption (See Figure S2). Indeed, only 15 to $20 \%$ of the manometrically injected $\mathrm{C}_{2} \mathrm{H}_{5} \mathrm{I}$ is recovered as $\mathrm{H}$ atom behind the reflected shock wave. This discrepancy is attributed to the adsorption of the highly diluted $\mathrm{C}_{2} \mathrm{H}_{5} \mathrm{I}$ at the walls of the storage/mixing vessel, and had been already observed by Woiki and Roth ${ }^{43}$ when using the exact same experimental device. As a consequence, $\mathrm{C}_{2} \mathrm{H}_{5} \mathrm{I}$ was not used for $\mathrm{H}$-atom calibration and other reacting systems were considered. In the following, the calibration proposed by Kunz et al. is adopted as it has been obtained in temperature (1300-1900 K) and pressure (1.5-1.7 atm) ranges which are similar to those employed in the present experiments and with a reacting system $\left(\mathrm{N}_{2} \mathrm{O} / \mathrm{H}_{2}\right)$ preventing wall adsorption.

Such losses on the walls of the storage vessel were only observed for $\mathrm{C}_{2} \mathrm{H}_{5} \mathrm{I}$, therefore ensuring that the initial $\mathrm{SiCl}_{4}$ concentrations are accurately known. In order to model the reactivity of $\mathrm{SiCl}_{4} / \mathrm{C}_{2} \mathrm{H}_{5} \mathrm{I}$ mixtures diluted in argon, the initial $\mathrm{C}_{2} \mathrm{H}_{5} \mathrm{I}$ concentration was recovered from the early absorption profile (before any significant $\mathrm{H}$ atom consumption ), corrected from the absorption contribution of $\mathrm{SiCl}_{4}$ calculated from the temperature-dependent absorption cross sections published by Mével et al. $\left(\sigma_{\mathrm{SiCl}_{4}}=\right.$ $1.00110^{-16} \exp \left(-9.6910^{-6} \times T\right) \mathrm{cm}^{2}$ between 1400 and $\left.2000 \mathrm{~K}\right)$.

3.2.2.2. Comparison between experimental and simulated profiles 
Figure 11 compares the experimental absorption profiles at the $\mathrm{L}_{\alpha}$ wavelength with the one constructed from the modeling results obtained with the model proposed in this study. In this figure (and others) the computed profiles are constructed using Equation 2 in which $\sigma_{\mathrm{H}}$ is adopted from Kunz and Roth ${ }^{4}, \sigma_{\mathrm{SiCl} 4}$ is taken from Catoire et al. ${ }^{1}$, and the absorption cross sections of other silicon species adopted from Mevel et al. ${ }^{8}$ Comparisons at other temperatures and initial $\mathrm{SiCl}_{4}$ mole fractions are given in the supplementary materials.

Regardless of the initial conditions, both a qualitative and quantitative agreement is obtained between the experimental and simulated profiles, suggesting that the model offers a good description of $\mathrm{H}$ atom consumption. An analysis of the rate of consumption of $\mathrm{H}$-atom shows that, although the reaction of $\mathrm{SiCl}_{4}$ with $\mathrm{H}$-atom $\left(\mathrm{R}_{1}\right)$ accounts for most of the $\mathrm{H}$ atom scavenging at all temperatures, the reaction of $\mathrm{SiCl}_{3}$ radicals with $\mathrm{H}\left(\mathrm{R}_{6}\right)$ cannot be neglected. Indeed, if the contribution of reaction $\mathrm{R}_{6}$ is limited around $1500 \mathrm{~K}$ to $5-10 \%$ of $\mathrm{H}$ atom removal, this amount rises to about $30 \%$ at temperatures close to $1700 \mathrm{~K}$, highlighting the importance of the secondary chemistry and the requirement of accurate rate constants for these reactions.

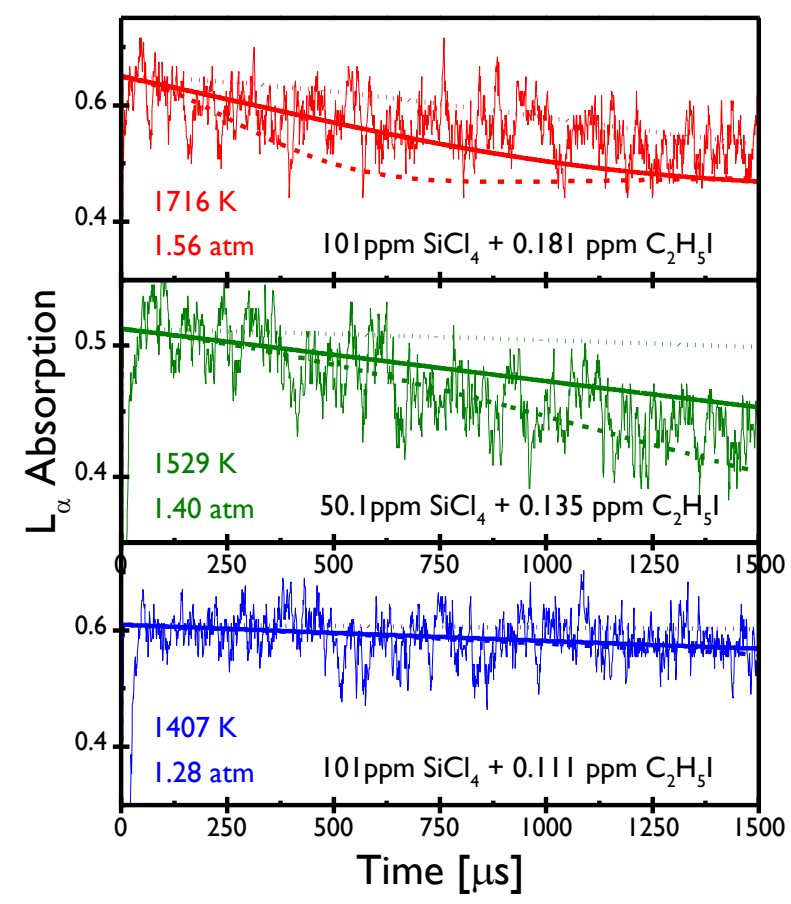

Figure 11: Comparison between the experimental and computed absorption profiles of $\mathrm{SiCl}_{4} / \mathrm{C}_{2} \mathrm{H}_{5} \mathrm{I} / \mathrm{Ar}$ at different temperatures and mixture composition. Ethyl iodide initial concentration is derived from the experimental profile (see text). The dashed and dotted lines depict the effect of substituting the herein calculated rate constants of reaction $R_{1}$ and $R_{2}$ with the published values of Zhang et al. ${ }^{3}$ (dotted line) and Kunz and Roth ${ }^{4}$ (dashed line), respectively.

3.2.2.3. Sensitivity and rate of production analysis

A brute-force sensitivity analysis has been performed to identify the most sensitive reactions. The sensitivity coefficients were defined as $S_{i}=d \ln A / d \ln k_{i}$ where A is the computed absorption and $\mathrm{k}_{\mathrm{i}}$ 
the rate constant of the $\mathrm{i}^{\text {th }}$ reaction (in the detailed kinetic model). Aside from the ethyl iodide decompositions reactions $\left(S_{86}=-S_{87}=0.04\right)$, the most sensitive reaction for temperatures around $1500 \mathrm{~K}$ is reaction $\mathrm{R}_{1}$, with a sensitivity coefficient $\mathrm{S}_{1}=-0.06$. Other reactions involving $\mathrm{SiCl}_{\mathrm{x}}$ species are not sensitive at this temperature. At $\sim 1700 \mathrm{~K}$, whereas reaction $\mathrm{R}_{1}$ remains the most sensitive reaction $\left(\mathrm{S}_{1}=\right.$ $-0.09)$, the absorption profile now exhibits a certain sensitivity to reactions $R_{3}$ and $R_{6 a}\left(S_{3}=S_{6 a}=-0.02\right)$. Regardless of the temperature, the absorption is not sensitive to the reactions of the $\mathrm{C}_{2} \mathrm{H}_{5} / \mathrm{C}_{2} \mathrm{H}_{4}$ subset although those reactions are the direct source of $\mathrm{H}$-atom production.

With regards to the results of the sensitivity analysis, the absorption profiles have been computed with the present model in which either the rate constant of reaction $\mathrm{R}_{1}$ was replaced by the theoretical value of Zhang et al. ${ }^{3}$ or the rate constant of reaction $\mathrm{R}_{2}$ was adopted from Kunz and Roth ${ }^{4}$. The computed profiles then obtained are displayed in Figure 11 as dashed and dotted lines. Consistent with the sensitivity coefficients discussed above, modifying the rate constants of these two reactions strongly affects both the absorption intensity and profile shape. At the lowest temperature, the effect of modifying $\mathrm{k}_{1}$ and $\mathrm{k}_{2}$ is very limited, although the lower value of $\mathrm{k}_{1}$ results in a flat absorption profile. At the intermediate temperature ( $1529 \mathrm{~K})$, the rate constant of Kunz and Roth, which is higher than the herein recommended $\mathrm{k}_{2}$, results in a faster decay of the mixture absorption coefficient, however still within the experimental values. On the other hand, the absorption profile obtained with the rate constant of Zhang et al. is nearly flat, indicating an underestimation of the $\mathrm{H}$-atom consumption rate. At the highest temperature (1716K), the opposite observations can be made: the rate constant of Kunz and Roth strongly overestimate the initial decay of the absorption profile, followed by a plateau, while employing the rate constant of Zhang et al. enables capturing the experimentally observed profile.

\subsection{3. $\quad \mathrm{SiCl}_{4} / \mathrm{H}_{2}$ mixtures}

Although the updated model shows good performances against $\mathrm{SiCl}_{4} / \mathrm{C}_{2} \mathrm{H}_{5} \mathrm{I}$ experimental results, it does not necessarily imply that it has predictive ability for all $\mathrm{Si} / \mathrm{H} / \mathrm{Cl}$ systems. The use of several other initial mixtures is necessary to further validate the present model. One of these systems is $\mathrm{SiCl}_{4} / \mathrm{H}_{2}$ because not only it is probing the $\mathrm{Si} / \mathrm{H} / \mathrm{Cl}$ system reactivity but, as indicated in the introduction, is also relevant to practical applications.

\subsubsection{Comparison between experimental and simulated profiles}

Figure 12 displays the comparison between the experimental absorption profile $\mathrm{s}$ and those computed with the present model for one initial mixture composition in the temperature range 1500-1800 K. Further comparisons are available in the supplementary materials.

The present model captures, regardless of the temperature and the mixture composition, the initial rise of the absorption profile due to the thermal decomposition of $\mathrm{SiCl}_{4}$ and the subsequent reaction of $\mathrm{Cl}$ atoms with $\mathrm{H}_{2}$. Likewise, the plateau is also well reproduced by the model, suggesting the model offers 
an accurate description of the formation (reactions $R_{2}$ and $R_{14}$ ) and consumption (reactions $R_{1}$ and $R_{6}$ ) of $\mathrm{H}$ atoms in these mixtures and thermodynamic conditions. The sensitivity of the calculated profiles to the kinetic parameters is discussed below, as well as the effect of employing the rate constants of Kunz and Roth ${ }^{4}$, Zhang et al. ${ }^{3}$ or Mielke et al. ${ }^{36}$ on the predicted absorption profiles.

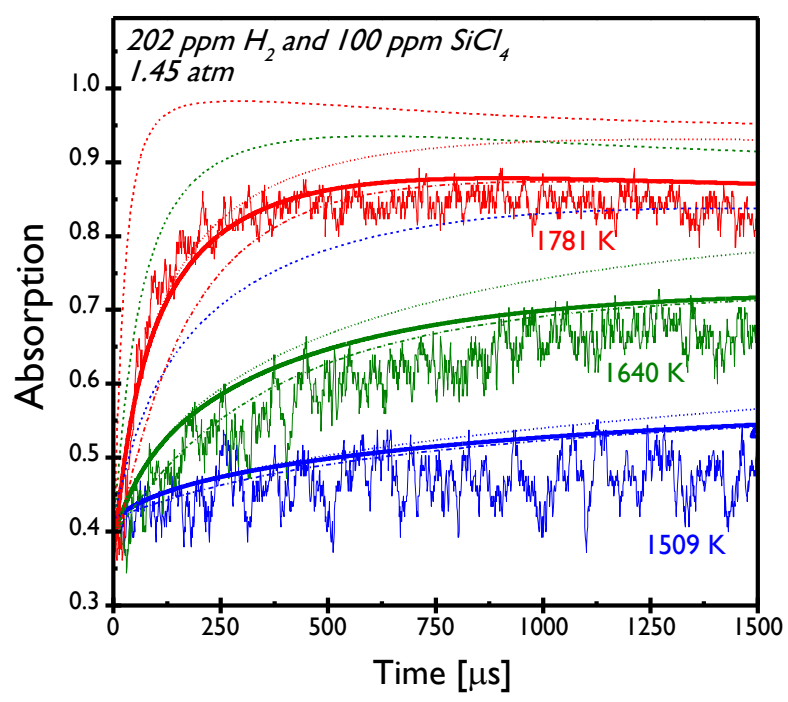

Figure 12: Comparison between the experimental and modeled (thick solid line) absorption profiles of $\mathrm{SiCl}_{4} / \mathrm{H}_{2}$ mixtures $\left(X_{\mathrm{H}_{2}} / X_{\mathrm{SiCl}_{4}} \approx 2\right)$ in $\mathrm{Ar}$ at three different temperatures. The thin dashed, dotted and dash-dotted lines depict the effect of substituting the herein calculated rate constants of reaction $\mathrm{R}_{1}, \mathrm{R}_{2}$, and $\mathrm{R}_{14}$ with the published values of Zhang et al. ${ }^{3}$ (dotted line), Kunz and Roth ${ }^{4}$ (dashed line), and Mielke et al. ${ }^{36}$ (dash-dotted line) is displayed, respectively.

\subsubsection{Sensitivity and rate of production analysis}

Path-flux and sensitivity analysis have been performed to identify the governing reactions in the reactivity of the $\mathrm{SiCl}_{4} / \mathrm{H}_{2}$ mixtures. Regardless of the temperature or the $\mathrm{SiCl}_{4} / \mathrm{H}_{2}$ ratio, about $70 \%$ of the consumed tetrachloride silicon reacts through the unimolecular decomposition $\mathrm{R}_{2}$ and the remaining $30 \%$ by reaction with $\mathrm{H}$-atom. The chlorine atoms released by $\mathrm{SiCl}_{4}$ decomposition almost exclusively interact with $\mathrm{H}_{2}$ through reaction $\mathrm{R}_{14}$, which is the main (>99\%) $\mathrm{H}$-atom source. The other $\mathrm{SiCl}_{4}$ decomposition product, namely $\mathrm{SiCl}_{3}$, exhibits a similar reaction pattern than its parent fuel. Indeed, about one third ( $35 \%$ ) further decomposes into singlet dichlorosilylene while 50 to $60 \%$ (this amount increases with the temperature) reacts with $\mathrm{H}$ atom through reaction $\mathrm{R}_{6}$. Nevertheless, at the lowest temperatures investigated in this study, about $10 \%$ of $\mathrm{SiCl}_{3}$ reacts with $\mathrm{H}_{2}$ to generate trichlorosilane $\mathrm{SiHCl}_{3}$ and an $\mathrm{H}$-atom. Finally, $\mathrm{H}$ atoms mostly react with $\mathrm{SiCl}_{4}$ and $\mathrm{SiCl}_{3}$. However, whereas at temperature close to $1500 \mathrm{~K}$, reaction $\mathrm{R}_{6}$ accounts for only $10 \%$ of $\mathrm{H}$-atom consumption, this proportion rises to $50 \%$ for the highest temperatures investigated herein, overtaking reaction $R_{1}(\sim 45 \%)$.

Sensitivity analysis reveals that the absorption profile is mostly sensitive to two reactions. As it could be expected, the most sensitive, by far, reaction is the $\mathrm{SiCl}_{4}$ decomposition channel with a strong promoting effect. The sensitivity coefficient $S_{2}$ increases from 0.08 at $1500 \mathrm{~K}$ to $\sim 0.135$ at $1640 \mathrm{~K}$, then 
decreases as the temperature further rises. The second most sensitive reaction is the reaction $\mathrm{R}_{1}$, with a negative sensitivity coefficient $S_{1}$ regardless of the temperature. Like $S_{2}$, the value of $S_{1}$ is temperature dependent and exhibits a minimum around $1700 \mathrm{~K}$. Therefore, as already observed with the $\mathrm{SiCl}_{4} / \mathrm{C}_{2} \mathrm{H}_{5} \mathrm{I}$ mixtures, the accuracy of the rate constants $\mathrm{k}_{1}$ and $\mathrm{k}_{3}$ is critical to reach a fair agreement between the simulated and experimental absorption profile s. Figure 12 also illustrates the effect of substituting our values of $k_{2}$ and $k_{1}$ with those of Kunz and Roth ${ }^{4}$ and Zhang et al. ${ }^{3}$, respectively. In the first case $\left(k_{2}\right)$, the initial build-up rate of the $\mathrm{H}$ atom pool is overestimated, resulting in a stronger absorption over the whole observation time window. In the second case, the effect of changing $\mathrm{k}_{1}$ is observed after about 250-400 $\mu$ s and results in an overestimation of the absorption, therefore of the H-atom concentration, as the depletion of $\mathrm{H}$-atom radical pool is slowed down.

When increasing the temperature ( $>1750 \mathrm{~K}$ ), the reactions $\mathrm{R}_{3}$ and $\mathrm{R}_{6}$ involving the $\mathrm{SiCl}_{3}$ radical become sensitive, with coefficients $S_{3} \approx 0.02$ and $S_{6} \approx-0.03$. This is consistent with the results of the path flux analyses, in which $\mathrm{SiCl}_{3}$ was observed to become the main $\mathrm{H}$ atom scavenger at high temperatures.

Surprisingly, in spite of the central role of the $\mathrm{H}_{2}+\mathrm{Cl}$ reaction $\left(\mathrm{R}_{14}\right)$ in generating $\mathrm{H}$-atoms, the absorption profile is weakly sensitive $\left(S_{14}=0.01\right)$ to the rate constant of this reaction. Nevertheless, adopting the rate constant of Mielke et al for $\mathrm{R}_{14}$ results in a slower increase (see Figure 12) of the Hatom pool build-up, especially at high temperatures, suggesting that the value of $\mathrm{k}_{14}$ is of importance when $\mathrm{SiCl}_{4}$ decomposition is no more the limiting step in the $\mathrm{H}$ production mechanism.

\section{Conclusions}

The reactivity of $\mathrm{SiCl}_{4} / \mathrm{C}_{2} \mathrm{H}_{5} \mathrm{I}$ and $\mathrm{SiCl}_{4} / \mathrm{H}_{2}$ mixtures diluted in argon behind a shock wave has been investigated experimentally by monitoring the absorbance at the Lyman $\alpha$ wavelength. The experimental profiles, resulting for a large extent from the absorption of $\mathrm{H}$ atoms and $\mathrm{SiCl}_{\mathrm{x}}$ species, were expected to be mostly sensitive to the thermal decomposition of $\mathrm{SiCl}_{4}\left(\mathrm{R}_{2}\right)$ and its reaction with $\mathrm{H}$ atoms $\left(\mathrm{R}_{1}\right)$.

The rate constants of these two reactions, as well as those of the reaction of $\mathrm{SiCl}_{3}\left(\mathrm{R}_{6}-\mathrm{R}_{8}\right)$ and $\mathrm{SiCl}_{2}\left(\mathrm{R}_{9}\right.$ $\mathrm{R}_{11}$ ) with $\mathrm{H}$ atoms, have been calculated theoretically based on $\operatorname{CCSD}(\mathrm{T}) /$ aug-cc-pV $\infty \mathrm{Z} / \mathrm{B} 2 \mathrm{PLYP}$ D3/aug-cc-pVTZ or NEVPT2/aug-cc-pV $\infty Z$, energetics depending on the multi-reference character of the structures involved. Canonical TST calculations were performed for bimolecular reaction whereas VTST and RRKM theory combined with master equation analysis were carried out to access the pressure effect on the $\mathrm{SiCl}_{4}$ or $\mathrm{SiHCl}_{3}$ decomposition rate constant, among others. The calculated rate constants were found to differ substantially from previously reported values, either due to the neglect of the pressure dependence or discrepancies in the ab initio parameters.

The calculated temperature and pressure dependent rate constants (Table 3) have been implemented in an updated model, which has then been successfully tested and validated against the experimental data. Sensitivity analysis showed that an accurate description of both $\mathrm{SiCl}_{4}$ decomposition and $\mathrm{SiCl}_{4}+\mathrm{H}$ 
kinetics was mandatory to match the experimental observations, definitely ruling the experimental determination of the $\mathrm{SiCl}_{4}$ thermolysis rate constant $\mathrm{k}_{2}$ by Kunz and Roth ${ }^{4}$ out. Rate of consumption analyses using the updated model highlighted the importance of $\mathrm{SiCl}_{3}$ chemistry to the $\mathrm{H}$ atom pool consumption at high temperatures, as $\mathrm{SiCl}_{4}$ concentration decreases.

The above conclusion that the experimental value of Kunz and Roth for $\mathrm{SiCl}_{4}$ decomposition must be discarded raises the question of the validity of the companion rate constants determined in their study. These reactions consist in the decomposition of $\mathrm{SiCl}_{3}, \mathrm{SiCl}_{2}$, and $\mathrm{SiCl}$ species. Although the present experimental results are not sensitive to these reactions, they may play a significant role under different conditions and therefore would deserve to be investigated in a future work, all the more so as the absorption cross sections used in the present work for these three species ${ }^{8}$ were obtained in the framework of Kunz and Roth kinetics.

\section{Supporting Information}

Scheme of the experimental setup employed in the present study; Results of the sensitivity analysis on $\mathrm{k}_{2}$; H-atom experimental concentration profiles during the decomposition of neat $\mathrm{C}_{2} \mathrm{H}_{5} \mathrm{I}$ (in $\mathrm{Ar}$ ); Comparison between experimental and modeled absorption profiles; Interaction potentials for $\mathrm{SiCl}_{4}+$ $\mathrm{He}, \mathrm{SiHCl}_{3}+\mathrm{He}$, and $\mathrm{SiHCl}_{2}+\mathrm{He}$; Cartesian coordinates, scaled frequencies and moments of inertia of reactants, products, and saddle points discussed in this study. This material is available free of charge via the Internet at http://pubs.acs.org.

\section{$\underline{\text { Acknowledgment }}$}

This work did not receive any specific grant from funding agencies in the public, commercial, or notfor-profit sectors. 


\section{REFERENCES}

(1) Catoire, L.; Woiki, D.; Roth, P. A Shock Tube Study of the Reaction of H Atoms with SiCl4. Int. J. Chem. Kinet. 1997, 29 (6), 469-472. https://doi.org/10.1002/(SICI)10974601(1997)29:6<469::AID-KIN9>3.0.CO;2-S.

(2) Ge, Y.; Gordon, M. S.; Battaglia, F.; Fox, R. O. Theoretical Study of the Pyrolysis of Methyltrichlorosilane in the Gas Phase. 3. Reaction Rate Constant Calculations. J. Phys. Chem. A 2010, 114 (6), 2384-2392. https://doi.org/10.1021/jp911673h.

(3) Zhang, X.; Ding, Y. H.; Li, Z. S.; Huang, X. R.; Sun, C. C. Ab Initio Study on the Rate Constants of $\mathrm{SiCl} 4+\mathrm{H} \rightarrow \mathrm{SiCl} 3+\mathrm{HCl}$. Phys. Chem. Chem. Phys. 2001, 3 (6), 965-969. https://doi.org/10.1039/b006856j.

(4) Kunz, A.; Roth, P. High-Temperature Kinetics of Some Si- and Cl-Containing Ceramic Precursors. Int. J. Chem. Kinet. 2001, 33 (11), 741-754. https://doi.org/10.1002/kin.1071.

(5) Ravasio, S.; Masi, M.; Cavallotti, C. Analysis of the Gas Phase Reactivity of Chlorosilanes. J. Phys. Chem. A 2013, 117 (25), 5221-5231. https://doi.org/10.1021/jp403529x.

(6) Thielen, K.; Roth, P. Resonance Absorption Measurements of $\mathrm{N}$ and $\mathrm{O}$ Atoms in High Temperature No Dissociation and Formation Kinetics. Symp. Combust. 1985, 20 (1), 685-693. https://doi.org/10.1016/S0082-0784(85)80558-0.

(7) Woiki, D.; Catoire, L.; Roth, P. High-Temperature Kinetics of Si-Containing Precursors for Ceramic Processing. AIChE J. 1997, 43 (S11), 2670-2678. https://doi.org/10.1002/aic.690431311.

(8) Mével, R.; Catoire, L.; Fikri, M.; Roth, P. Measurement of the Absorption Cross Sections of $\mathrm{SiCl} 4, \mathrm{SiCl} 3, \mathrm{SiCl} 2$ and $\mathrm{Cl}$ at $\mathrm{H}$ Lyman- $\alpha$ Wavelength. Chem. Phys. Lett. 2013, 561-562, 3135. https://doi.org/10.1016/j.cplett.2013.01.035.

(9) Reaction Design, Inc., San Diego, 2018. CHEMKIN PRO Release 19.2.

(10) Frisch, M. J.; Trucks, G. W.; Schlegel, H. B.; Scuseria, G. E.; Robb, M. A.; Cheeseman, J. R.; Scalmani, G.; Barone, V.; Mennucci, B.; Petersson, G. A.et al., Gaussian 09, Revison D01. Gaussian, Inc., Wallinford CT 2013.

(11) Kesharwani, M. K.; Brauer, B.; Martin, J. M. L. Frequency and Zero-Point Vibrational Energy Scale Factors for Double-Hybrid Density Functionals (and Other Selected Methods): Can Anharmonic Force Fields Be Avoided? J. Phys. Chem. A 2015, 119 (9), 1701-1714. https://doi.org/10.1021/jp508422u.

(12) Kanchanakungwankul, S.; Bao, J. L.; Zheng, J.; Alecu, I. M.; Lynch, B. J.; Zhao, Y.; Truhlar, D. G. Database of Frequency Scale Factors for Electronic Model Chemistries-Version 4.

(13) Neese, F. The ORCA Program System. Wiley Interdiscip. Rev. Comput. Mol. Sci. 2012, 2 (1), 73-78. https://doi.org/10.1002/wcms.81.

(14) Neese, F. Software Update: The ORCA Program System, Version 4.0. Wiley Interdiscip. Rev. Comput. Mol. Sci. 2018, 8 (1). https://doi.org/10.1002/wcms.1327.

(15) Dunning, T. H. Gaussian Basis Sets for Use in Correlated Molecular Calculations. I. The Atoms Boron through Neon and Hydrogen. J. Chem. Phys. 1989, 90 (2), 1007-1023. https://doi.org/10.1063/1.456153.

(16) Barker, J. R.; Nguyen, T. L.; Stanton, J. F.; Aieta, C.; Ceotto, M.; Gabas, F.; Kumar, T. J. D.; Li, C. G. L.; Lohr, L. L.; Maranzana, A.; Ortiz, N. F.; Preses, J. M.; Simmie, J. M.; Sonk, J. A.; Stimac, P. J. MultiWell-2020 Software Suite. University of Michigan: Ann Arbor, Michigan, USA 2020.

(17) Glowacki, D. R.; Liang, C. H.; Morley, C.; Pilling, M. J.; Robertson, S. H. MESMER: An OpenSource Master Equation Solver for Multi-Energy Well Reactions. J. Phys. Chem. A 2012, 116 (38), 9545-9560. https://doi.org/10.1021/jp3051033.

(18) Jasper, A. W.; Miller, J. A. Theoretical Unimolecular Kinetics for $\mathrm{CH} 4+\mathrm{M} \rightleftarrows \mathrm{CH} 3+\mathrm{H}+\mathrm{M}$ in Eight Baths, $\mathrm{M}=\mathrm{He}, \mathrm{Ne}, \mathrm{Ar}, \mathrm{Kr}, \mathrm{H} 2, \mathrm{~N} 2, \mathrm{CO}$, and CH4. J. Phys. Chem. A 2011, 115 (24), 
6438-6455. https://doi.org/10.1021/jp200048n.

(19) Moore, T.; Brady, B.; Martin, L. R. Measurements and Modeling of SiCl4 Combustion in a LowPressure H2/O2 Flame. Combust. Flame 2006, 146 (3), 407-418. https://doi.org/10.1016/j.combustflame.2006.06.003.

(20) Ge, Y.; Gordon, M. S.; Battaglia, F.; Fox, R. O. Theoretical Study of the Pyrolysis of Methyltrichlorosilane in the Gas Phase. 2. Reaction Paths and Transition States. J. Phys. Chem. A 2007, 111 (8), 1475-1486. https://doi.org/10.1021/jp065455a.

(21) Su, M. Der; Schlegel, H. B. Heats of Formation of SiHmCln Calculated by Ab Initio Molecular Orbital Methods. J. Phys. Chem. 1993, 97 (34), 8732-8735. https://doi.org/10.1021/j100136a014.

(22) Bauschlicher, C. W.; Partridge, H. The Heats of Formation of SiCln+, for $\mathrm{n}=1-4$. Chem. Phys. Lett. 1997, 276 (1-2), 47-54. https://doi.org/10.1016/s0009-2614(97)88033-5.

(23) Li, Q. S.; Xu, X. D.; Zhang, S. Predicting Energies and Geometries for Reactions Involved in Atmosphere Chemistry: A Comparison Study between Hybrid DFT Methods. Chem. Phys. Lett. 2004, 384 (1-3), 20-24. https://doi.org/10.1016/j.cplett.2003.11.060.

(24) Rollmann, G.; Entel, P. Interaction of Atomic Hydrogen with Silane Molecules. In Phase Transitions; Taylor \& Francis Group , 2004; Vol. 77, pp 139-147. https://doi.org/10.1080/01411590310001623274.

(25) Walch, S. P.; Dateo, C. E. Thermal Decomposition Pathways and Rates for Silane, Chlorosilane, Dichlorosilane, and Trichlorosilane. J. Phys. Chem. A 2001, 105 (10), 2015-2022. https://doi.org/10.1021/jp003559u.

(26) Zhang, F.; Nicolle, A.; Xing, L.; Klippenstein, S. J. Recombination of Aromatic Radicals with Molecular Oxygen. Proc. Combust. Inst. 2017, 36 (1), 169-177. https://doi.org/10.1016/j.proci.2016.06.021.

(27) Harding, L. B.; Georgievskii, Y.; Klippenstein, S. J. Predictive Theory for Hydrogen AtomHydrocarbon Radical Association Kinetics. J. Phys. Chem. A 2005, 109 (21), 4646-4656. https://doi.org/10.1021/jp0508608.

(28) Walch, S. P.; Dateo, C. E. Reactions of $\mathrm{SiCl} 2$ and $\mathrm{SiHCl}$ with $\mathrm{H}$ and $\mathrm{Cl}$ Atoms. J. Phys. Chem. A 2002, 106 (12), 2931-2934. https://doi.org/10.1021/jp0126154.

(29) Jasper, A. W.; Klippenstein, S. J.; Harding, L. B. The Effect of Spin-Orbit Splitting on the Association Kinetics of Barrierless Halogen Atom-Hydrocarbon Radical Reactions. J. Phys. Chem. A 2010, 114 (18), 5759-5768. https://doi.org/10.1021/jp1015092.

(30) Catoire, L.; Woiki, D.; Roth, P. Kinetics of the Initiation Step of the Thermal Decomposition of SiCl4. Int. J. Chem. Kinet. 1997, 29 (6), 415-420. https://doi.org/10.1002/(SICI)10974601(1997)29:6<415::AID-KIN2>3.0.CO;2-X.

(31) Kumaran, S. S.; Su, M. C.; Lim, K. P.; Michael, J. V.; Wagner, A. F.; Harding, L. B.; Dixon, D. A. Ab Initio Calculations and Three Different Applications of Unimolecular Rate Theory for the Dissociations of CCl4, CFCl3, CF2Cl2, and CF3Cl. J. Phys. Chem. 1996, 100 (18), 7541-7549. https://doi.org/10.1021/jp9600470.

(32) Lee, J. H.; Michael, J. V.; Payne, W. A.; Stief, L. J.; Whytock, D. A. Absolute Rate of the Reaction of Cl(2P) with Molecular Hydrogen from 200-500 K. J. Chem. Soc. Faraday Trans. 1 Phys. Chem. Condens. Phases 1977, 73 (0), 1530-1536. https://doi.org/10.1039/F19777301530.

(33) Kita, D.; Stedman, D. H. Kinetic Studies of Reactions of Hydrogen Atoms with $\mathrm{HCl}, \mathrm{Cl} 2$ and $\mathrm{NOCl}$, and Chlorine Atoms with $\mathrm{H} 2$ and NOCl. J. Chem. Soc. Faraday Trans. 2 Mol. Chem. Phys. 1982, 78 (8), 1249-1259. https://doi.org/10.1039/F29827801249.

(34) Adusei, G. Y.; Fontijn, A. Experimental Studies of Cl-Atom Reactions at High Temperatures: $\mathrm{Cl}+\mathrm{H} 2 \rightarrow \mathrm{HCl}+\mathrm{H}$ from 291 to 1283 K. Symp. Combust. 1994, 25 (1), 801-808. https://doi.org/10.1016/S0082-0784(06)80713-7.

(35) Kumaran, S. S.; Lim, K. P.; Michael, J. V. Thermal Rate Constants for the $\mathrm{Cl}+\mathrm{H} 2$ and $\mathrm{Cl}+\mathrm{D} 2$ Reactions between 296 and 3000 K. J. Chem. Phys. 1994, 101 (11), 9487-9498. https://doi.org/10.1063/1.468486. 
(36) Mielke, S. L.; Allison, T. C.; Truhlar, D. G.; Schwenke, D. W. Quantum Mechanical Rate Coefficients for the $\mathrm{Cl}+\mathrm{H} 2$ Reaction. J. Phys. Chem. 1996, 100 (32), 13588-13593. https://doi.org/10.1021/jp960782b.

(37) Ruscic, B.; Bross, D. H. Active Thermochemical Tables (ATcT) values based on ver. 1.122g of the Thermochemical Network (2019); available at ATcT.anl.gov.

(38) Mével, R.; Javoy, S.; Dupré, G. A Chemical Kinetic Study of the Oxidation of Silane by Nitrous Oxide, Nitric Oxide and Oxygen. Proc. Combust. Inst. 2011, 33 (1), 485-492. https://doi.org/10.1016/j.proci.2010.05.076.

(39) Zhou, C. W.; Li, Y.; Burke, U.; Banyon, C.; Somers, K. P.; Ding, S.; Khan, S.; Hargis, J. W.; Sikes, T.; Mathieu, O.; Petersen, E. L.; AlAbbad, M.; Farooq, A.; Pan, Y.; Zhang, Y.; Huang, Z.; Lopez, J.; Loparo, Z.; Vasu, S. S.; Curran, H. J. An Experimental and Chemical Kinetic Modeling Study of 1,3-Butadiene Combustion: Ignition Delay Time and Laminar Flame Speed $\begin{array}{lllll}\text { Measurements. } & \text { Combust. } & \text { Flame } & \text { 2018, } & \text { 197, }\end{array}$ https://doi.org/10.1016/j.combustflame.2018.08.006.

(40) Varga, T.; Zsély, I. G.; Turányi, T.; Bentz, T.; Olzmann, M. Kinetic Analysis of Ethyl Iodide Pyrolysis Based on Shock Tube Measurements. Int. J. Chem. Kinet. 2014, 46 (6), 295-304. https://doi.org/10.1002/kin.20829.

(41) Yang, X.; Tranter, R. S. High-Temperature Dissociation of Ethyl Radicals and Ethyl Iodide. Int. J. Chem. Kinet. 2012, 44 (7), 433-443. https://doi.org/10.1002/kin.20601.

(42) Kumaran, S. S.; Su, M. C.; Lim, K. P.; Michael, J. V. The Thermal Decomposition of C2H5I. Symp. Combust. 1996, 26 (1), 605-611. https://doi.org/10.1016/S0082-0784(96)80266-9.

(43) Woiki, D.; Roth, P. A Shock Tube Study of the Reactions of H Atoms with COS, CS ${ }_{2}$, and $\mathrm{H}_{2}$ S. Isr. J. Chem. 1996, 36 (3), 279-283. https://doi.org/10.1002/ijch.199600039. 
Table of Content Graphic Abstract

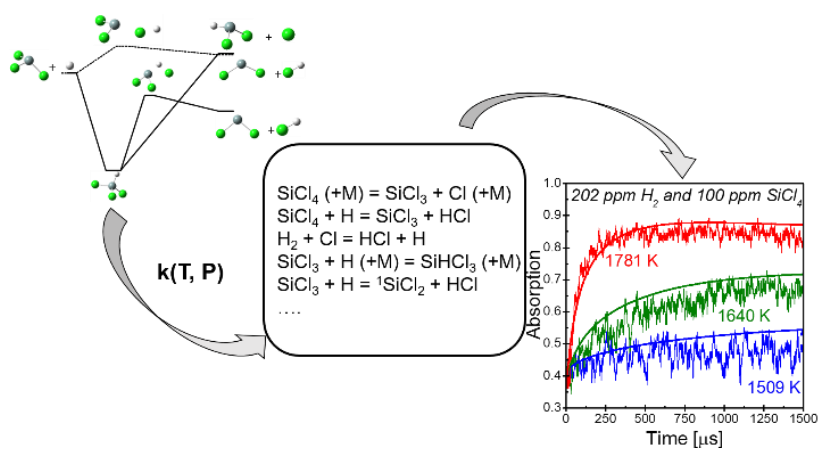

